\title{
Closely related Campylobacter jejuni strains from different sources reveal a generalist rather than a specialist lifestyle
}

Eugenia Gripp ${ }^{1}$, Daniela Hlahla', Xavier Didelot ${ }^{2}$, Friederike Kops ${ }^{1}$, Sven Maurischat ${ }^{3}$, Karsten Tedin $^{3}$, Thomas Alter ${ }^{4,7}$, Lüppo Ellerbroek ${ }^{4}$, Kerstin Schreiber ${ }^{5}$, Dietmar Schomburg 5 , Traute Janssen ${ }^{3}$, Patrick Bartholomäus ${ }^{1}$, Dirk Hofreuter ${ }^{1}$, Sabrina Woltemate ${ }^{1}$, Markus Uhr ${ }^{1}$, Birgit Brenneke ${ }^{1}$, Petra Grüning ${ }^{6}$, Gerald Gerlach ${ }^{6}$, Lothar Wieler ${ }^{2}$, Sebastian Suerbaum ${ }^{1 *}$ and Christine Josenhans ${ }^{*}$

\begin{abstract}
Background: Campylobacter jejuni and Campylobacter coli are human intestinal pathogens of global importance. Zoonotic transmission from livestock animals or animal-derived food is the likely cause for most of these infections. However, little is known about their general and host-specific mechanisms of colonization, or virulence and pathogenicity factors. In certain hosts, Campylobacter species colonize persistently and do not cause disease, while they cause acute intestinal disease in humans.

Results: Here, we investigate putative host-specificity using phenotypic characterization and genome-wide analysis of genetically closely related C. jejuni strains from different sources. A collection of 473 fresh Campylobacter isolates from Germany was assembled between 2006 and 2010 and characterized using MLST. A subset of closely related C. jejuni strains of the highly prevalent sequence type ST-21 was selected from different hosts and isolation sources. PCR typing of strain-variable genes provided evidence that some genes differed between these strains. Furthermore, phenotypic variation of these strains was tested using the following criteria: metabolic variation, protein expression patterns, and eukaryotic cell interaction. The results demonstrated remarkable phenotypic diversity within the ST-21 group, which however did not correlate with isolation source. Whole genome sequencing was performed for five ST-21 strains from chicken, human, bovine, and food sources, in order to gain insight into ST-21 genome diversity. The comparisons showed extensive genomic diversity, primarily due to recombination and gain of phage-related genes. By contrast, no genomic features associated with isolation source or host were identified.

Conclusions: The genome information and phenotypic data obtained in vitro and in a chicken infection model provided little evidence of fixed adaptation to a specific host. Instead, the dominant C. jejuni ST-21 appeared to be characterized by phenotypic flexibility and high genetic microdiversity, revealing properties of a generalist. High genetic flexibility might allow generalist variants of $C$. jejuni to reversibly express diverse fitness factors in changing environments.
\end{abstract}

\section{Background}

Intestinal infections by Campylobacter jejuni and Campylobacter coli are, jointly with Salmonella enterica infections, the most frequent bacterial causes of diarrheal diseases of humans worldwide [1]. C. jejuni causes the

\footnotetext{
* Correspondence: suerbaum.sebastian@mh-hannover.de; josenhans. christine@mh-hannover.de

'Institute for Medical Microbiology, Hannover Medical School, Hannover, Germany

Full list of author information is available at the end of the article
}

majority (> 83\%) of human symptomatic Campylobacter infections [2]. Campylobacter ssp. are transmitted mainly by contaminated food of animal origin [3-8]. Animals are frequently infected persistently with Campylobacters and, in most cases, show no symptoms, contrary to the acute and self-limiting intestinal infection caused in humans. The cause of these discrepant outcomes of infection in different hosts is not clear, although previous work has suggested that host as well as bacterial factors may
C Biomed Central

() 2011 Gripp et al; licensee BioMed Central Ltd. This is an Open Access article distributed under the terms of the Creative Commons Attribution License (http://creativecommons.org/licenses/by/2.0), which permits unrestricted use, distribution, and reproduction in any medium, provided the original work is properly cited. 
contribute [9-13]. Numerous $C$. coli and $C$. jejuni subtypes with similar morphology and biochemistry are found in different mammalian and bird hosts, with the possibility of zoonotic transmission to humans. In addition, Campylobacter species display extensive intraspecies variation. These properties require sophisticated molecular typing methods in order to differentiate species and subtypes, and to elucidate infection sources. Multi Locus Sequence Typing (MLST) analyses have proven to be a molecular method of choice and previously have provided clear evidence that genetically related strains of either $C$. jejuni or $C$. coli can colonize different hosts [13-19]. These strains frequently are part of large clonal complexes, whose members share most of the MLST alleles. However, MLST studies rely solely on the analysis of seven housekeeping genes, belonging to the core genome [16], and disregard the rest of the $\sim 1.7 \mathrm{Mb}$ genome [20], which includes virulence-associated genes as well as possible strain-specific genes or gene variants. Thus, the question remains open, whether different strain subtypes infecting humans differ from animal-colonizing and food-associated types within one closely related genetic grouping (such as an MLST sequence type).

Little is known about the mechanisms of host-specific colonization, virulence and pathogenicity factors of Campylobacter species. With few exceptions [21,22], genome sequences currently available in databases for Campylobacter species (see: NCBI "Microbial Genomes"; http:// www.ncbi.nlm.nih.gov/genomes; [23,24]) have been derived from human isolates, therefore genome information about strains from other sources is still scarce. In order to complement these recent advances, it may be relevant to gather more information about host association and animal-associated strains and subtypes, some of which may be more prone to be transmitted or cause severe complications during human infections. Prophylactic measures are required to prevent transmission from food and animals to humans, which also require a better knowledge of strain-to-strain variability and adaptation potential to different hosts and environments such as food. This study was designed to characterize the genetic relationships and population structure of $C$. jejuni and $C$. coli currently prevalent in humans, domestic animals and food sources in Germany. Furthermore, a major aim was to establish the extent of diversity within dominant phylogenetic groups of $C$. jejuni from this collection, which are present in diverse hosts, such as ST-21, with regard to their different sources.

To that end, we collected $473 C$. jejuni and C. coli isolates from humans, as well as animal (poultry, porcine, bovine), food, and environmental isolates between 2006 and 2010 in Germany. MLST analysis and extensive molecular typing of the isolates was performed, which confirmed C. jejuni ST-21 as one of the dominant "generalist" variants occurring in all sources. Further phenotypic characterization and whole genome analyses of closely related ST-21 C. jejuni strains from different sources provided little evidence for host or source-associated traits. Nevertheless, ST-21 isolates from different sources displayed a high genomic and phenotypic diversity and flexibility. Domestic circulating C. jejuni STs such as ST-21 appear to use mechanisms such as interstrain recombination, metabolic and surface-associated genetic modules and contingency genes to permit a generalist lifestyle and the flexible expression of fitness factors in diverse environments.

\section{Results}

\section{Multi Locus Sequence Typing of $C$. coli and $C$. jejuni} isolates from diverse isolation sources in humans, animals and food sources

We collected 473 Campylobacter strains (173 C. coli and 300 C. jejuni) from animal hosts (chicken, pigs, cattle, wild birds, monkeys, pet animals), human patients, and food sources over a five-year period (2006 to 2010) in several geographically separate centers in Germany. Human patient samples were collected in three university hospitals (Hannover, Munich, Muenster); the majority of nonpatient isolates were from domestic animals and food samples, while few strains originated from wild-living animals. Molecular typing of the whole strain collection was performed by MLST [15,25]. 197 different sequence types (STs; 112 for $C$. jejuni and 85 for C. coli) were identified, of which 57 were new STs not previously represented in the PubMLST database. These new STs include 37 that are novel combinations of previously known alleles, and 20 that included 19 novel alleles (further statistics, including separate analyses for C. coli and C. jejuni, in Table 1). The ST distribution was highly diverse, with 121 STs occurring only once, and the ten most common STs comprising only $43.7 \%$ and $48.0 \%$ of isolates for C. jejuni and C. coli, respectively. Of the 76 STs represented more than once, 22 were found in humans and, in addition, in either animals or food or in both of the latter, suggesting a host range consistent with zoonotic potential. All STs contained either only C. jejuni or C. coli strains. Only two alleles were found to occur in both species, $p g m 188$, present in $4 C$. coli and $2 C$. jejuni strains, and $u n c A 17$, a very common allele present in $131 \mathrm{C}$. coli and 7 C. jejuni strains. Minimal spanning trees were generated from the MLST data illustrating the phylogenetic relationships of the strains (Figure 1). In confirmation and extension of previous results, MLST revealed dominant sequence types within the strains (Figure 1 and Additional File 1: Table S1). The dominant sequence types in the FBI-Zoo collection partially overlapped with dominant sequence types reported for Campylobacter samplings in the United Kingdom, the Netherlands, the U.S., Canada, Denmark and 
Table 1 MLST analysis of FBI-Zoo Campylobacter strain collection

\begin{tabular}{|c|c|}
\hline Number of strains & 473 \\
\hline - C. jejuni & 300 \\
\hline - C. coli & 173 \\
\hline \multicolumn{2}{|l|}{ Source (C. jejuni/C. coli) } \\
\hline human patients & $134(117 / 17)$ \\
\hline Animals & $210(90 / 120)$ \\
\hline Food & $129(93 / 36)$ \\
\hline \multicolumn{2}{|l|}{ MLST } \\
\hline Number of STs in dataset & 197 \\
\hline - occurring in multiple strains & 76 \\
\hline - singletons & 121 \\
\hline novel STs & 57 \\
\hline novel alleles & 19 \\
\hline 10 most frequent C. jejuni STs & no. of strains per ST (percent) strains from animals/food/human patients \\
\hline ST-50 & $34(11.3 \%) 9 / 5 / 20$ \\
\hline ST-21 & $27(9.0 \%) 6 / 11 / 10$ \\
\hline$\underline{\text { ST-572 }}$ & $13(4.3 \%) 1 / 7 / 5$ \\
\hline ST-45 & $12(4.0 \%) 3 / 4 / 5$ \\
\hline ST-48 & $9(3.0 \%) 2 / 3 / 4$ \\
\hline ST-1073 & $8(2.7 \%) 2 / 2 / 4$ \\
\hline$\underline{\text { ST-61 }}$ & $7(2.3 \%) 1 / 3 / 3$ \\
\hline ST-257 & $7(2.3 \%) 2 / 1 / 4$ \\
\hline ST-5408 & $7(2.3 \%) 7 / 0 / 0$ \\
\hline$\underline{\text { ST-5411 }}$ & $7(2.3 \%) 7 / 0 / 0$ \\
\hline 10 most frequent $C$. coli STs & no. of strains per ST (percent) strains from animals/food/human patients \\
\hline ST-854 & $15(8.7 \%)$ 14/0/1 \\
\hline ST-1117 & $11(6.4 \%)$ 11/0/0 \\
\hline ST-5411 & $7(4.0 \%) 7 / 0 / 0$ \\
\hline ST-825 & $6(3.5 \%) 4 / 2 / 0$ \\
\hline ST-1628 & $6(3.5 \%) 2 / 1 / 3$ \\
\hline ST-829 & $5(2.9 \%) 2 / 3 / 0$ \\
\hline ST-3016 & $5(2.9 \%) 1 / 3 / 1$ \\
\hline ST-5372 & $5(2.9 \%) 5 / 0 / 0$ \\
\hline ST-5379 & $4(2.3 \%) 4 / 0 / 0$ \\
\hline ST-1556 & $4(2.3 \%) 4 / 0 / 0$ \\
\hline \multicolumn{2}{|c|}{$\underline{\text { Standardized Index of Association (sIA) }}$} \\
\hline all strains & 0.45 \\
\hline C. coli only & 0.07 \\
\hline C. jejuni only & 0.45 \\
\hline \multicolumn{2}{|l|}{ eBURST V3 analysis } \\
\hline No. of groups (strains included) & $19(385)$ \\
\hline singleton strains & 88 \\
\hline
\end{tabular}

Finland (Additional File 2: Figure S2), which provide the majority of MLST types previously deposited in the public MLST database (Campylobacter PubMLST; http:// PubMLST.org), and in some other countries. This result suggests that Campylobacter sequence types prevalent in many geographic areas of the world represent similar dominant strain types and clonal complexes. The five most dominant MLST sequence types for $C$. jejuni in the strain collection were ST-50, ST-21, ST-572, ST-45, St-48, and for C. coli ST-854, ST-1117, ST-5411, ST-825, and 

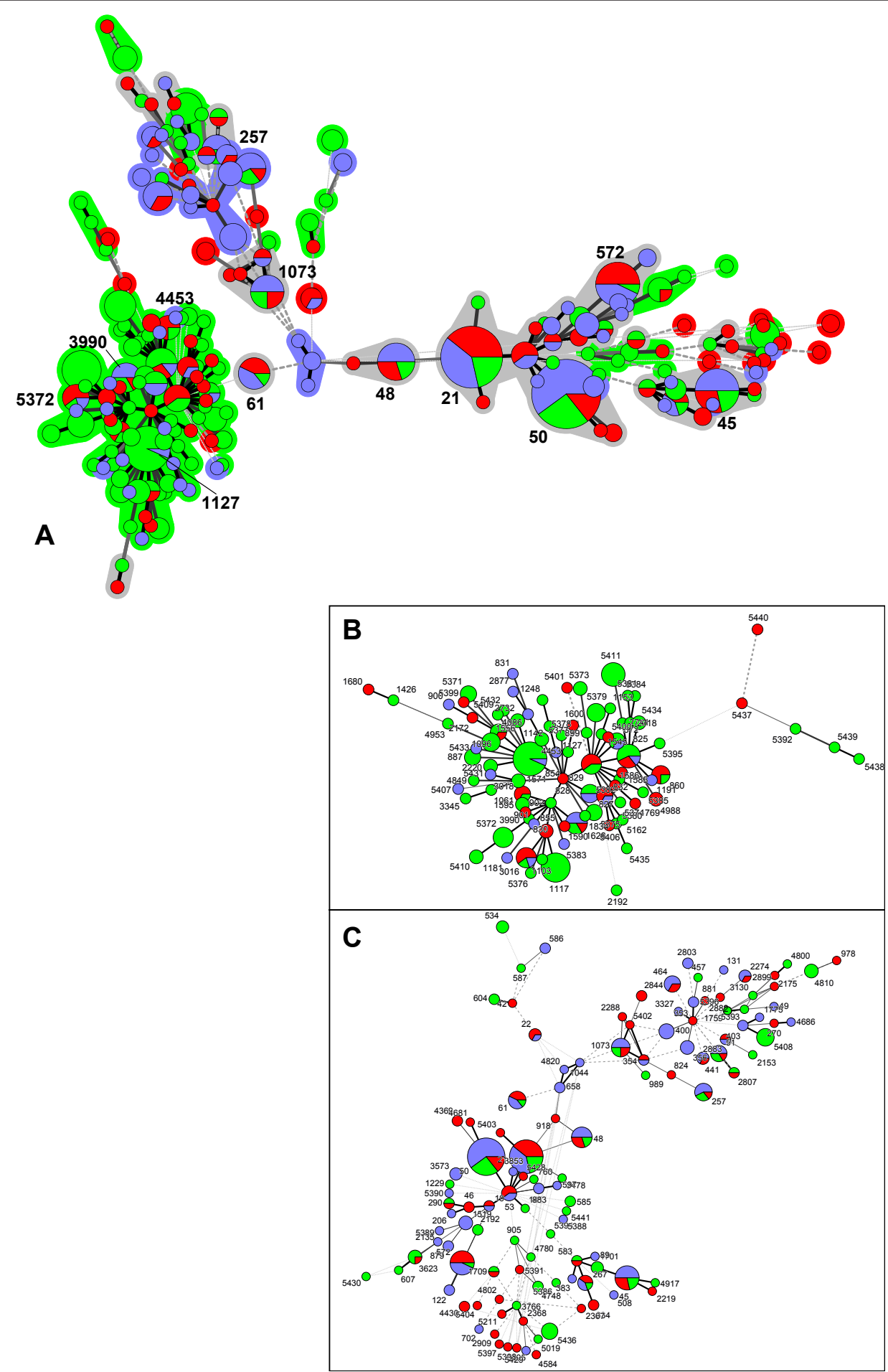

Figure 1 Phylogenetic analysis of Campylobacter FBI-Zoo strain collection from humans, animals and food sources by MLST (Minimal Spanning Tree analysis-methods). A) Minimal spanning tree generated from MLST comparisons of all Campylobacter strains from the

collection (Methods). B) Minimal spanning tree of C. coli strains. C) Minimal spanning tree of C. jejuni strains. Each circle represents one sequence type (all ST numbers indicated in B and C). In A), only dominant STs are indicated by numbers. Circles of increased diameter represent higher strain numbers within one ST. Different colours indicate strain source: blue-human; red-food; green-animal. The connecting lines between STS depict the number of allelic differences between them: one allele difference (black bold lines); two alleles difference (grey bold lines [A] or thin lines $[B, C]$ ); three alleles difference (grey hatched lines); more than three alleles difference (grey dotted lines). The phylogenetic group on the left of ST-61 represents all C. coli isolates, the phylogenetic tree expanding to the right of ST-61 comprises the C. jejuni strains. Clonal groupings (maximum two allele difference between neigbouring STs) in A) are indicated by colored shading around the circles and dominant STs within important groupings are designated with their respective ST numbers. The shading of clonal groupings is colored according to the majority isolation source. Grey shading indicates no predominance of source within the clonal groupings. 
ST-1628. Many common MLST types, such as ST-21, ST45, ST-48, were distributed rather evenly between strains isolated from domestic animal, human and food sources (Figure 1, Table 1). Some, mostly rarer, strain types were only found either in animals, food sources or in humans. C. coli strains were more closely related to each other than the C. jejuni strains (Figure 1), in concordance with previous studies [26,27].

The standardized Index of Association, $\left(\mathrm{sI}_{\mathrm{A}}\right)$ [28], was calculated for the complete set of allelic profiles and separately for $C$. coli and $C$. jejuni strains, respectively. $\mathrm{sI}_{\mathrm{A}}$ was 0.45 for the complete dataset and the $C$. jejuni dataset, indicating a limited amount of recombination not sufficient to completely destroy linkage between alleles. By contrast, the $\mathrm{sI}_{\mathrm{A}}$ for the $C$. coli dataset was 0.07 , a value close to the expected value for linkage equilibrium (free recombination).

\section{Extended genetic pathotyping of Campylobacter jejuni}

Due to the restriction of the Campylobacter MLST system to seven housekeeping genes, potential host-specific genes, genes providing strain-specific means of enhanced survival and transmission, or predictive markers for infection-associated severe disease may only be detected by looking at an enhanced set of proposed virulence genes, or at the complete genomes of strains. We therefore selected a subgroup of C. jejuni strains (91 strains; Additional File 2: Table S2) from the FBI-Zoo collection that contained representative isolates of all dominant MLST sequence types, and included strains from all major available isolation sources (human, diverse animals, food materials) for all dominant STs. Each strain in this subset was subjected to PCR-based typing to detect the presence or absence of a panel of 18 genes previously proposed to be involved in pathogenesis, metabolism or host specificity (Additional File 2: Table S2). Three additional genes were included for the typing of $55 \mathrm{C}$. jejuni strains belonging to ten different STs (Figure 2). A few tested genes were present in all strains, such as Cj0977, flaC, flaA, cadF, pglB, and flpA (proposed adhesin [29]). Most of the tested genes were only detectable in a subset of the strains, including $g g t$ (gamma-glytamyl-transpeptidase), secreted ansB (asparaginase), $d m s A, c d t B, f u c P, \operatorname{cia} B, \operatorname{cap} A$ (presumed adhesin [29]) and neuC1 (sialyltransferase) genes [12,30-32]. Both the ggt gene and the secreted $a n s B\left(a n s B_{s}\right)$ allelic variant were previously proposed to provide niche or host specificity $[12,31]$. Interestingly, the proportion of strains possessing ggt or $a n s B_{s}$ genes was overall very low in our strain collection $(<8 \%)$. In addition, in isogenic MLST groups containing strains from all three major isolation sources (human, food, animal), the presence of the neuC1, ggt or $a n s B_{s}$ genes did not correlate with isolation source. Nor did the presence of any other gene in the pathotyping matrix (Figure 2; Additional File 2: Table S2) correlate with isolation source. However, close correlation with MLST type was detected for the proposed virulence genes $f_{s p A 1}$ and $f_{s p A 2}$ [33], except for ST-21, suggesting that these gene types are usually coinherited in phylogenetically closely related strain subtypes. This result corroborates recent data for $f s p A 1$ obtained from Finnish strains [34]. Overall, taking into account phylogenetic relatedness of strains within ST groups, no correlation of presence of individual genes with the isolation source was observed. Additional genes involved in metabolic functions and iron uptake (exbB1, ceuB-E, $c r f A$ ) were tested for presence or absence in a subset of the 91 strains from different STs and isolation sources and did not show a host-specific distribution (not depicted). For some of the genes which were present in all or most strains ( $c d t B, f l a C, f l a A, c i a B)$ and some non-ubiquitous genes (neuC1, $d m s A, t l p 7, g g t$,

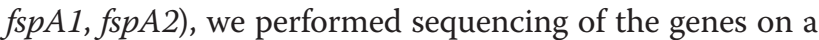
subset of PCR-typed strains (60 strains from 39 MLST sequence types; asterisks in Figure 2). Sequence diversity between the strains was found in these genes to a different extent (data not shown). In summary, none of the tested genes or allelic variants taken singly or in combination were correlated with isolation source.

\section{Evidence of phenotypic differences between \\ C. jejuni ST-21 strains from different sources}

The data described above suggested that the identification of any genes, gene variants or traits potentially providing host specificity to $C$. jejuni might require more sophisticated methodological approaches. We therefore decided to perform in-depth investigations of the phenotypic and genetic traits of eight selected $C$. jejuni strains from one single exemplary MLST sequence type (ST-21), a common and dominant ST worldwide. The selected ST-21 strains (xy259, A588, RB922, RB923, 6399, 7731, 04197, 04199; Figure 2) were isolated from human patients, domestic animals (cattle, chicken) and food sources; PCR typing of strain-variable genes (Figure 2) had provided evidence that some genes differed between these strains. This prompted us to first address the question whether these strains show any other phenotypic variation which would warrant further characterization with regard to the diversification of closely related strains. We tested the phenotypic variation of these strains using the following criteria: metabolic variation (Biolog PM1 plate, testing a panel of carbon-providing substrates including sugars and some amino acids; Additional File 2: Table S3), energy harvest, motility, morphology, protein expression patterns and cell interaction. Some of the experiments were performed at $42^{\circ} \mathrm{C}$ and at $37^{\circ} \mathrm{C}$. All of these freshly isolated strains possessed very high motility except for the milk-derived strain 6399 . The bacterial morphology in transmission electron microscopy was very similar. Cell interaction of the strains was comparatively tested in adherence assays with the human 


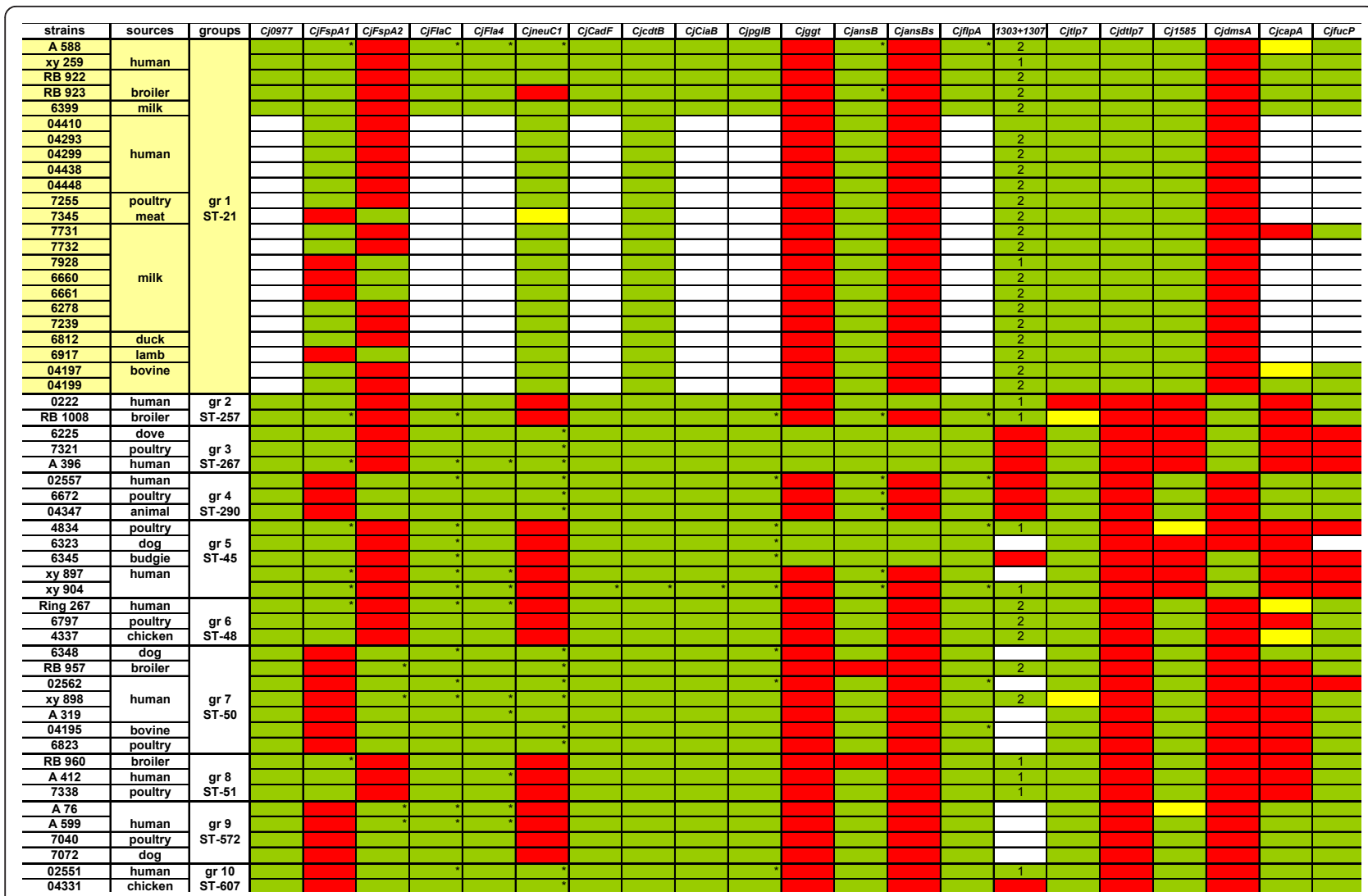

Figure 2 Pathotyping scheme of $\mathbf{5 5}$ C. jejuni strains ordered according to STs. Each of ten groups represents one ST and contains at least one strain from human, one strain from animal and one strain from food sources. The distribution of putative virulence- and host-associated genes was tested by PCR (primer combinations in Table 2). The presence of genes Cj1305 and Cj1306 was detected using a combination of primers in Cj1303 and Cj1307, by PCR product length: 1 indicates the presence of just one gene, either Cj1305 or Cj1306, and 2 indicates the presence of both genes. Color-coding: green: gene present; red: gene not present; yellow: weak PCR product; white: not tested. Gene copies marked by asterisks were additionally sequenced to identify interstrain polymorphisms using Sanger sequencing.

intestinal epithelial cell line $\mathrm{CaCo}$, the chicken macrophage-like cell line HD-11, the IPEC-J2 swine intestinal epithelial cell line (Figure 3) and human epithelial HeLa cells (not shown). In addition, proinflammatory cytokine production (data not shown) and cell activation were tested for eight ST-21 strains on the same cell lines containing an NF-kB-driven luciferase reporter (Figure 4). The tested ST-21 strains showed differences in cell adherence, cytokine production and NF-kB activation (Figure 3; Figure 4), indicating bacterial phenotypic differences. Next, we used rabbit-derived and chicken sera reactive against C. jejuni in order to compare the patterns of immunogenic proteins between different strains of the same sequence type in Western blots. Differential protein patterns were detected in closely related strains when cultivated at both $37^{\circ} \mathrm{C}$ and $42^{\circ} \mathrm{C}$ (data not shown). Likewise, MLST-isogenic strains differed in their metabolic properties and energy harvest as determined by Biolog analysis and intrabacterial ATP levels of eight ST-21 strains (Figure 5A, C, Additional File 2: Table S3). Interestingly, using the
Biolog characteristics, the group ST-21 strains could be largely subdivided into two phenotypic variants with characteristic patterns of properties. These two variants (biotype 1 and biotype 2) were represented with equal frequency in the eight strains (two strains each from human, chicken, bovine and milk sources) tested by Biolog, and did not show any correlation to a specific host or source. The common characteristics of half of these strains (biotype 2) were the metabolic use of three specific glycyl-L-dipeptides (glycyl-L-glutamic acid, glycyl-L-aspartic acid, glycyl-L-proline), L-galactonic acid g-lactone, tyramine, $\mathrm{m} / \mathrm{p}$-hydroxyphenylacetic acid (Figure 5A, Additional File 2: Table S3), while the biotype 1 strains did not use those. These metabolic trait differences had not been described before for closely related $C$. jejuni strains. These results were very reproducible and not temperature-dependent (expressed by the respective strains at both $37^{\circ} \mathrm{C}$ and $42^{\circ} \mathrm{C}$ ). When nine additional strains from other STs (human sources only, Figure 5A; Additional File 2: Table S3) were tested in the same Biolog system, distinct metabolic fingerprints 


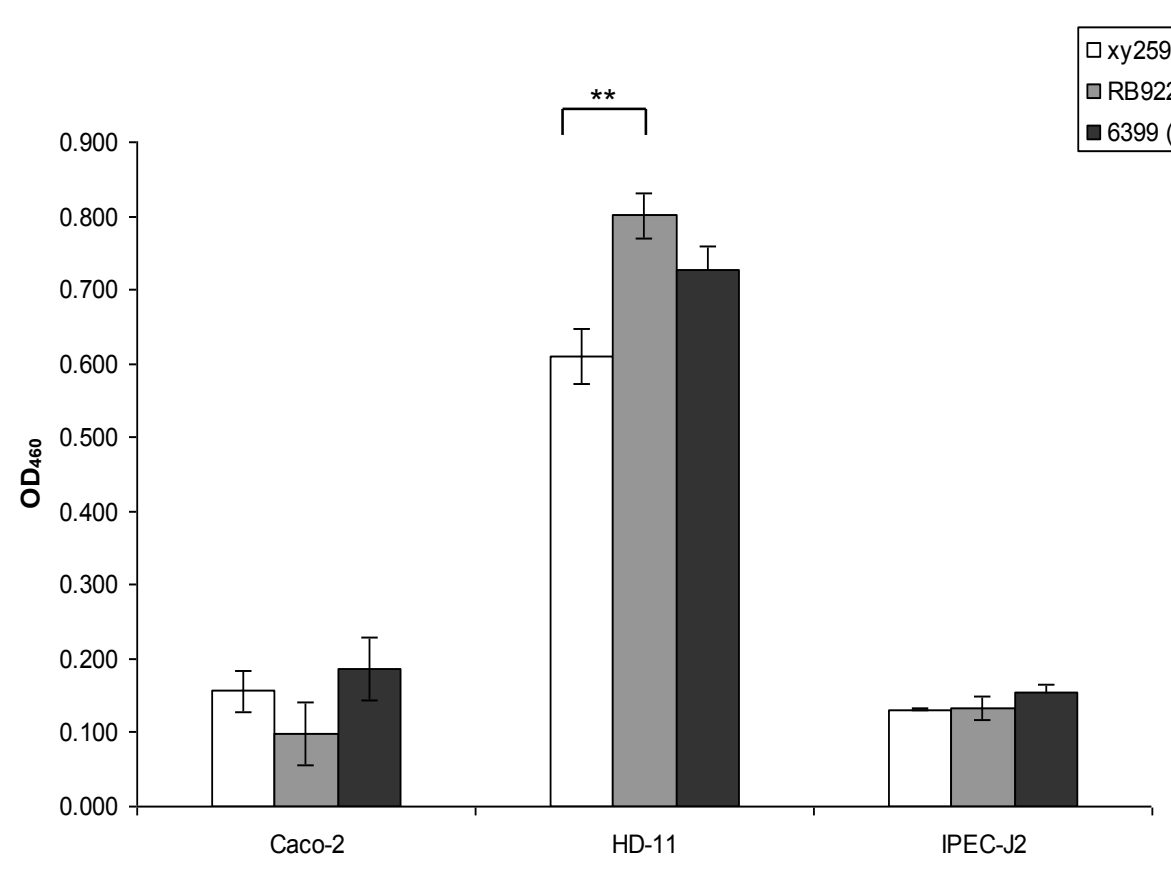

Figure 3 Phenotypic difference in adherence of three ST-21 C. jejuni strains from human, animal and food source to mammalian cells. Human colonic epithelial cells (CaCo-2), chicken macrophage-like cells (HD-11) and porcine intestinal epithelial cells (IPEC-J2) were infected in triplicates with biotin-labelled bacteria at an $\mathrm{MOI}$ of 200 and coincubated for $1 \mathrm{~h}$ (Methods). Each bar represents the mean \pm standard deviation number of adherent bacteria of one $C$. jejuni strain from triplicate measurement in one representative experiment. Statistical differences in adherence were evaluated using a Student's $t$ test. A $p$ value of $<0.05$ was considered statistically significant $\left({ }^{*} p \leq 0.05,{ }^{* *} p \leq 0.01\right.$, *** $p \leq$ 0.001). $h=$ human, $c h=$ chicken, $f=$ food.

were observed for each ST. Surprisingly, some of the tested strains also displayed increased electron chain activity with one hexose sugar (D-mannose) and one phosphate sugar (D-fructose-6-phosphate). In summary, these results provided clear evidence for phenotypic differences between ST-21 strains, with no indication of host specificity.
Complete genome analysis of genetically closely related C. jejuni ST-21 strains reveals interstrain variation

In order to test the hypothesis of a genetic basis for the observed phenotypic diversity within the ST-21 group, whole genome sequencing was performed for five ST-21 strains from bovine, chicken, human and food sources
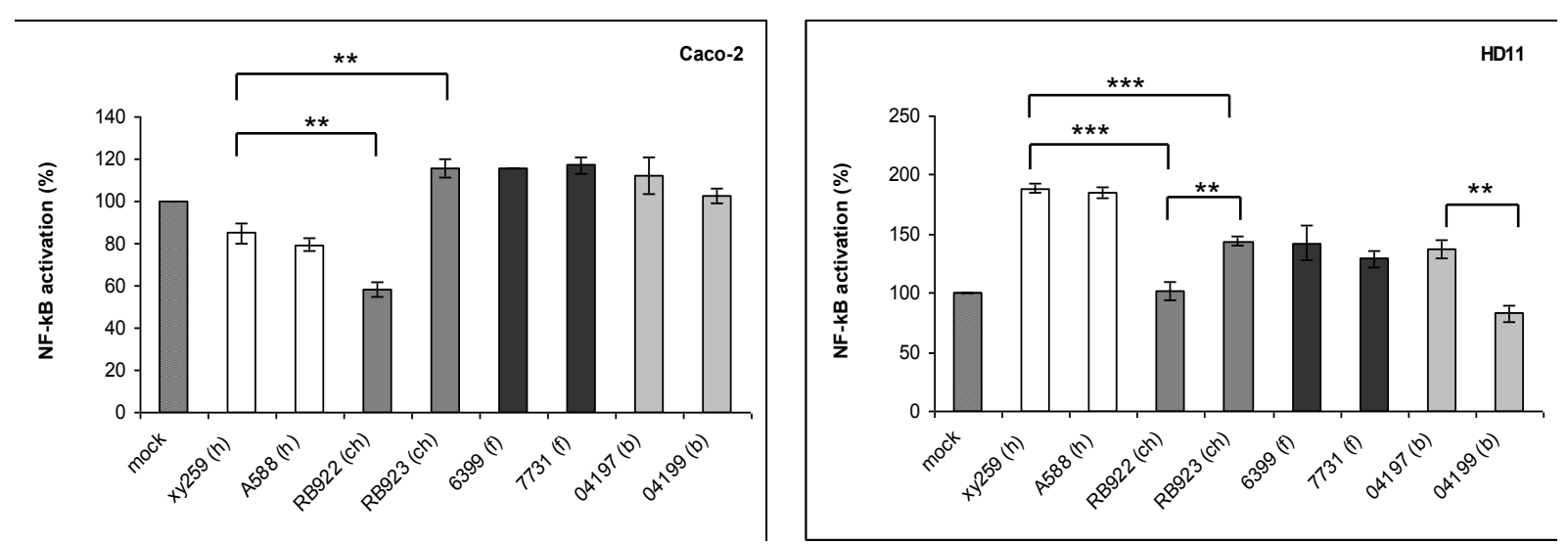

Figure 4 Differential NF- $\kappa$ B activation or inhibition by various ST-21 C. jejuni strains in mammalian cells. Stably transfected Caco- 2 cells (A) and HD-11 cells (B) containing a NF- $\kappa$ B-luciferase gene fusion were coincubated with 8 different $C$. jejuni strains (from human (h), chicken (ch), bovine (b) and food (f) source) at an $\mathrm{MOI}$ of 50 in triplicates and coincubated for $1 \mathrm{~h}$. The values are depicted in percent relative to the mock-infected sample, which was set to 100\%. One representative experiment of four is displayed. Statistics was performed using a Student's $t$ test. A p-value of $<0.05$ was considered statistically significant ( ${ }^{*} p \leq 0.05,{ }^{* *} p \leq 0.01,{ }^{* *} p \leq 0.001$ ). Selected statistical evaluation of differences between strains from one source or between two different sources is shown. 

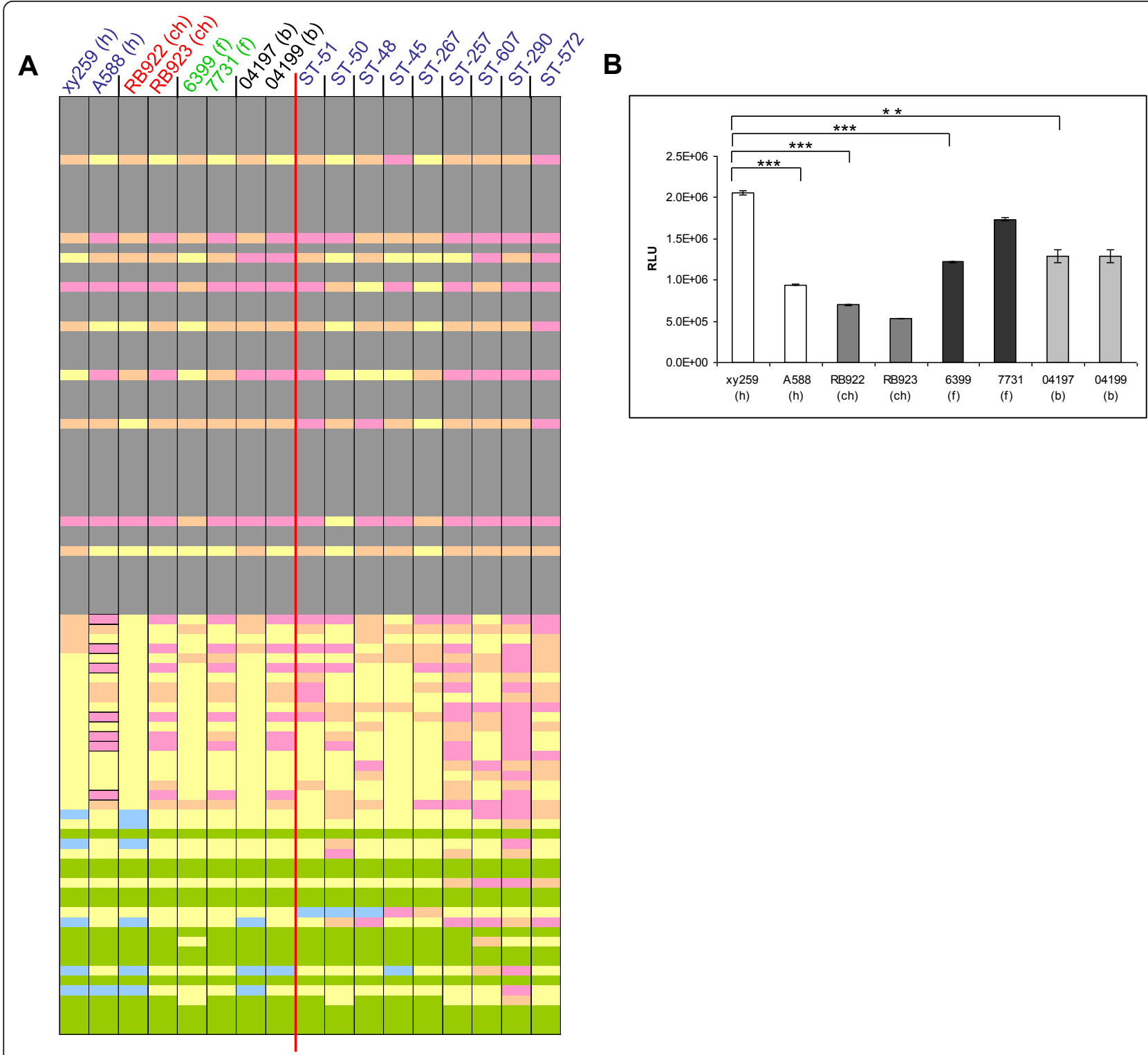

Figure 5 Differences between ST-21 C. jejuni strains in metabolic activity and energy levels. (A) Carbon source utilization by eight ST-21 strains (left panel) from different sources ( $h=$ human; $c h=$ chicken; $b=$ bovine; $f=$ food) and nine human-derived strains (from left to right: xy898, R267, xy904, A396, 222, 02551, 02557, A412 and A599) of different STs (right panel) were tested at $42^{\circ} \mathrm{C}$ using BioLog Phenotype Microarray PM1 plates (area values). Grey color indicates no or only weak substrate utilization for all strains (all area values below 800 ) and green indicates high substrate utilization for all strains (all area values above 800 ). The colors pink, yellow, beige and blue indicate strain-specific utilization: pink-zero utilization, beige- $<1,000$, yellow- $<9,000$, blue- $>9,000$. The six bordered rectangles on the left panel (from top to bottom, second from left column) indicate the substrates L-galactonic acid-g-lactone, tyramine, m-hydroxy-phenylacetic acid, p-hydroxy-phenylacetic acid, glycyl-L-aspartic acid, glycyl-L-glutamic acid and glycyl-L-proline, which are not used by some strains (phenotypic variant 1). PM1 experiments with ST-21 strains were performed at least three times independently on different days. Shown for each substrate are the mean area values of three independent experiments performed at $42^{\circ} \mathrm{C}$ for $30 \mathrm{~h}$ incubation time. PM1 experiments for other STs were performed either once or twice (mean values shown for ST-45 and ST-267 strains) at $42^{\circ} \mathrm{C}$. (B) Differences in intracellular ATP levels (energy harvest) of eight ST-21 strains from different sources. Statistics was performed using a Student's $t$ test. A p-value of $<0.05$ was considered statistically significant $\left(^{*} p \leq 0.05,{ }^{* *}\right.$ $\left.p \leq 0.01,{ }^{* * *} p \leq 0.001\right)$.

(strains: xy259, RB922, 6399, 04197, 04199; see Additional File 2: Table S4 for genome statistics). This approach was also aimed at answering the question, whether the observed phenotypic diversity was due to unique genomic events which could not be identified with pathotyping of known genes, and whether it was somehow correlated with association to a specific host. The genome sequences revealed relatively little variation 
in gene content (macrodiversity; Figure 6; Additional File 2: Table S5) but a high level of polymorphism within shared genes, contingency genes and intergenic regions (Figure 7 ). Those included single nucleotide (SNP) and clustered nucleotide polymorphisms (CNP) (Additional File 2: Figure S4 and Table S6). Sequence length differences were mostly found in intergenic regions (Additional File 2: Table S8). Four of the five sequenced strains had acquired phage gene clusters (Figure 6; Additional File 2: Tables S5, S9). Four selected phage genes were tested by specific PCR for their presence in a wider array of ST-21 strains and found to represent single events (Additional File 2: Table S9), uncorrelated with any host or source. The human isolate xy259 possessed a deletion in a gene responsible for surface or flagellar glycosylation (gene 617 family, gene Cj1305-like; Figure 6), which was not found in other human strains. The bovine strain 04197 lacked the gene equivalent to Cj0008 (gene designation of strain 11168), which is a gene of unknown function in a metabolic gene cluster relating to a pyridine nucleotide-disulphide oxidoreductase. The allelic diversity between the strains comprised a large number of synonymous and nonsynonymous nucleotide substitutions in coding regions (Additional File 2: Table S6), many of which originated from homologous recombination, and some deletions and insertions in both coding and intergenic regions of all strains (Additional File 2: Table S8). Repeat length differences probably originating from slipped strand mispairing mutagenesis were evident in all strains. This concerned eight genes of the glycosylation gene clusters leading to frameshifts in coding regions. We confirmed these repeat length differences in a larger number of ST-21 strains using Sanger sequencing (Additional File 2: Table S7). By this extended sequence determination, the repeat length differences obtained by 454 sequencing were confirmed, but none of the tested nucleotide polymorphisms was stably associated with the source of the strain. Only a limited number of single nucleotide polymorphisms and repeat differences could be investigated by this labour-intensive approach. Aligning the five genome sequences (Methods; Figure 7, Additional File 3: Table S10) revealed features of genome plasticity in $C$. jejuni, with a highly conserved overall synteny of the genomes. We detected that frequent homologous recombination events had happened since the divergence of the genomes from a common ancestor (Figure 7, Additional File 2: Table S6, Additional File 3: Table S10), with an average imported length of 1437 bp (maximum length of CNP up to $\sim 15 \mathrm{kbp}$ ). The genome regions containing clustered polymorphisms caused by recombination are summarized for all five ST-21 genomes in Additional File 2: Table S6. They contain genes of various functional categories (according to the COG classification). None of the functional categories showed significantly higher percentages for having undergone recombination than the average of all functional categories (Additional File 2: Figure S3). When the ST-21

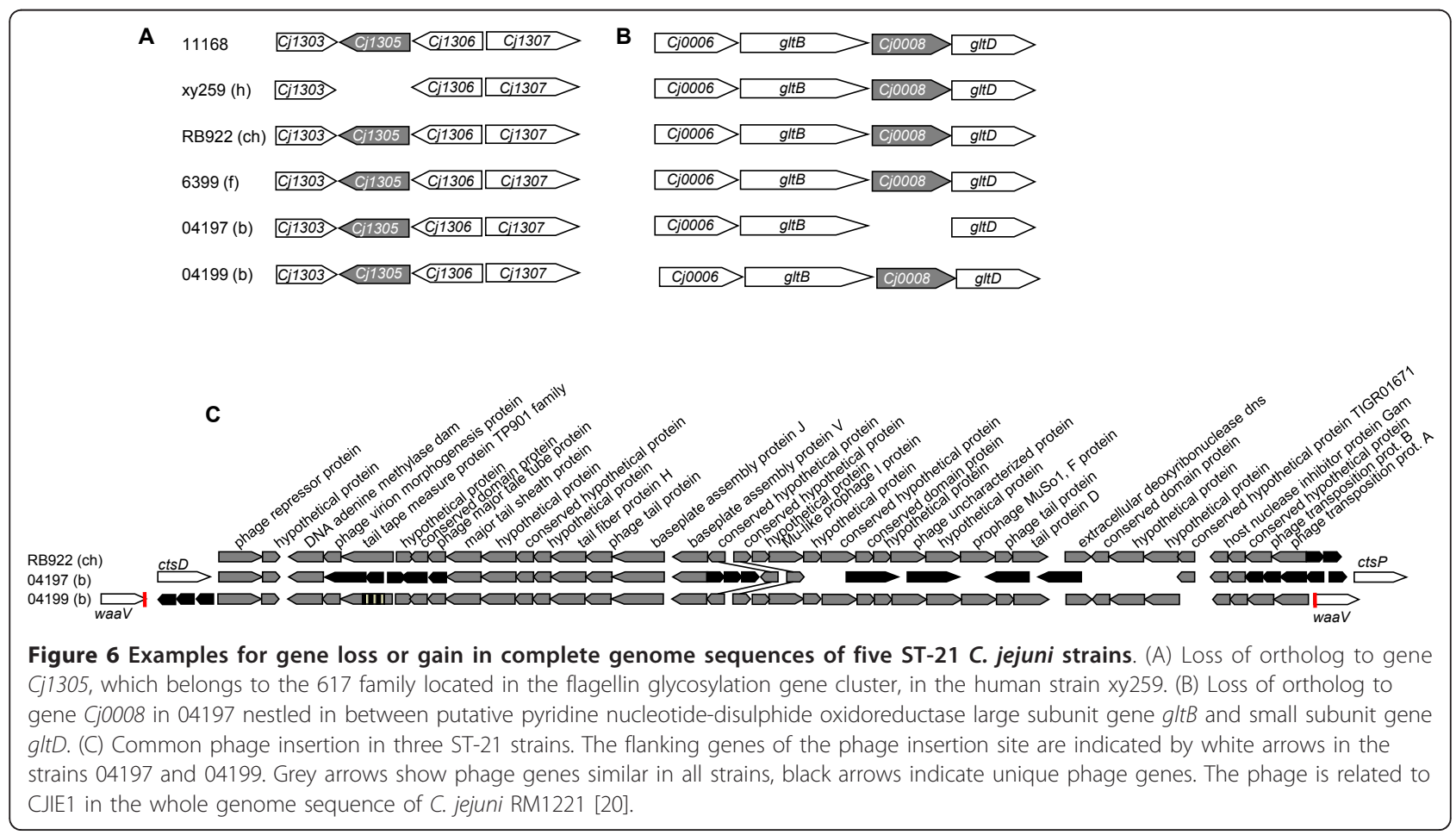




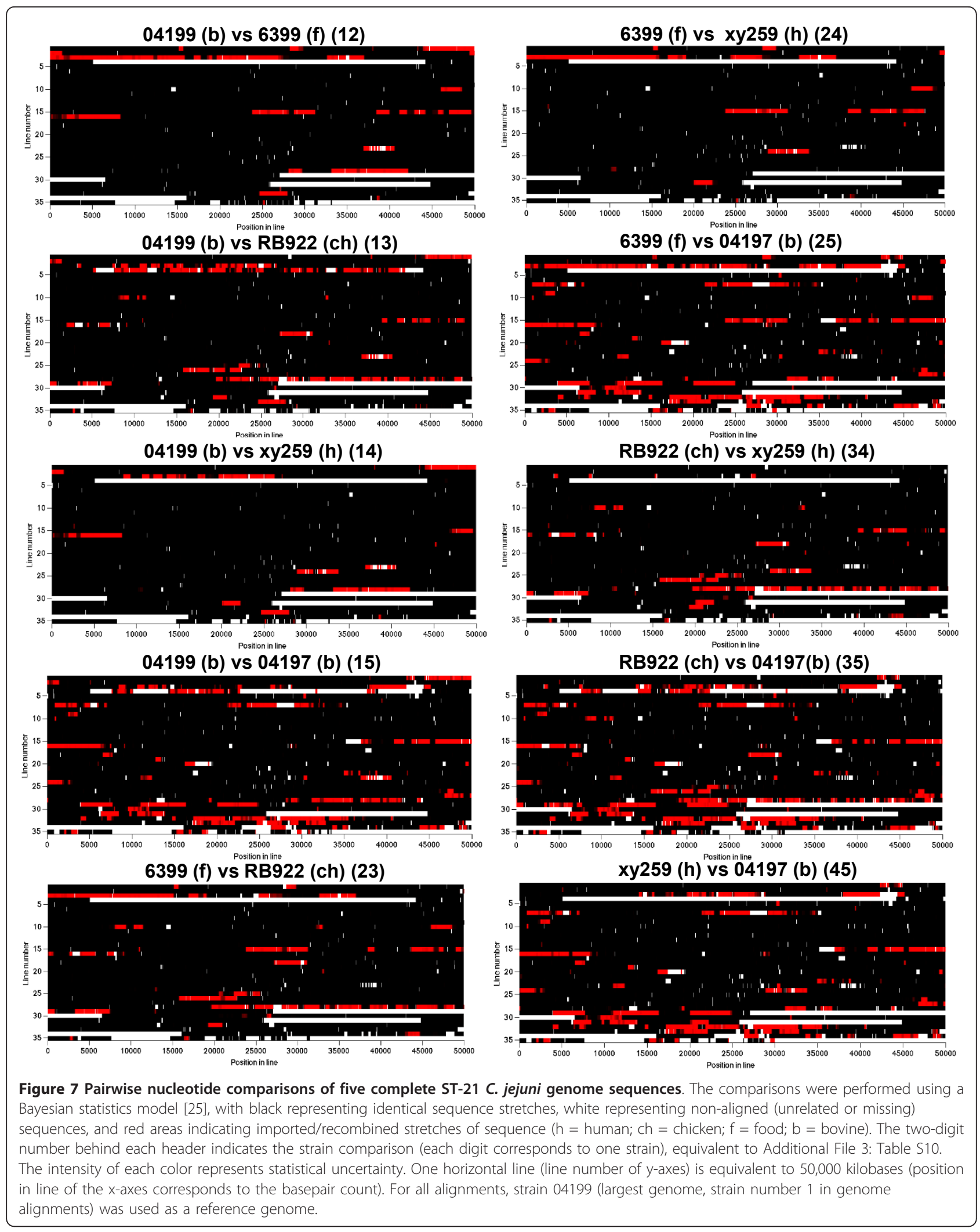


genomes were aligned to previously sequenced $C$. jejuni genomes from unrelated phylogenetic groups (e.g. of strains RM1221 [22] and 81176 [30]) in addition to nucleotide polymorphisms, notable differences in gene content were observed (mainly genes involved in metabolism, glycosylation, and restriction-modification genes; not shown).

\section{Correlating phenotypic variation with genetic differences in ST-21 strains}

Both genotypic and phenotypic differences were observed for ST-21 and other $C$. jejuni strains, and the genotypic differences might be a basis for a potential adaptive phenotype. From the Biolog assays, there was no evidence for a correlation of the two different metabolic biotypes within ST-21 with any specific source. Nevertheless, it is worthwhile investigating the gene variants potentially providing phenotypic differences, including those of metabolic capacities detected in the Biolog assay. We next asked if genetic polymorphisms within ST-21 that had been identified by the genome sequence analysis could be correlated with the metabolic biotypes. As already described previously, strains of the ST-21 lineage are able to use fucose, due to the presence of a genomic island $[35,36]$. As a proof of concept, use of fucose was confirmed for all tested ST-21 strains (which possess the fucose island in their complete genome sequences) using the Biolog system (Figure 5A). Within the other tested STs, ST-45 and ST-267 did not display fucose utilization, as expected from previous studies [35]. One of the ST-21 strains selected for whole genome sequencing, the bovine isolate 04199 , belonged to metabolic biotype 1 and did not metabolize the three dipeptides, tyramine, and m/p-hydroxy-phenylacetic acid. Although several genetic polymorphisms found in the 04199 genome were investigated in all ST-21 strains belonging to biotype 1 , and compared with the corresponding loci of biotype 2 strains, a specific genetic variant which could be responsible for the metabolic phenotype was not identified. Several genes and intergenic regions of potential relevance for metabolic activities varied between ST-21 strains (mostly sequence polymorphisms or small insertions/deletions; see also Additional File 2: Tables S6, S8). These included two peptidase genes [Cj0805-like, Cj0703-like], msrA [methionine sulfoxide reductase subunit], $c m e B$ [efflux pump subunit] (both genes contain polymorphisms in strain 04199), $s d h A$ [novel type fumarate dehydrogenase subunit; [37]], frdA [fumarate dehydrogenase subunit], $d c u B$ [C4-dicarboxylate transporter] (three genes contain polymorphisms in strain RB922), ansB [asparaginase], and $\operatorname{argS}$ [arginyltRNA synthetase] (the latter gene distinct in strain 6399). These allelic or intergenic differences were resequenced or tested with allele-specific primers for further isolates of ST21 and other STs from various sources. None of them could be affirmed to be source-associated or related to metabolic biotype for carbon sources. In addition, RNAbased real time PCR was performed for six ST-21 strains (five of which were the genome-sequenced isolates), two of biotype 1 and three of biotype 2 (04199 [1], A588 [1], xy259, 6399, RB922, 04197), to elucidate whether genes were differentially transcribed, in particular genes of global regulators. These analyses yielded clear differences in transcript abundance between the strains (for $r p o N, f l g R$ and luxS regulators) which were uncorrelated with metabolic biotype or source (not shown). Most conspicuously, strain 6399 (milk isolate) appeared to have a largely reduced rpoN transcript amount, which also seemed to negatively affect $l u x S$ transcript, and matched the low observed in vitro motility of this strain.

\section{Chicken colonization by two genetically closely related ST-21 C. jejuni strains from human and chicken} Chicken colonization studies have helped previously to determine whether certain $C$. jejuni variants were infection-competent, including studies that tested strains with presumed adaptation to other hosts that were no longer able to infect chickens [21]. We infected three weeks-old white leghorn chicks with two of the genome-sequenced closely related ST-21 strains, xy259 (human) and RB922 (chicken). All inoculated animals were colonized by both test strains, which had been verified in advance to possess full motility, since motility is a major prerequisite for successful colonization of campylobacters in any host and subject to strong phase variation mechanisms [38]. During the two-weeks' infection period, the chicken-derived strain colonized chickens slightly better (up to one log higher bacterial loads per animal) than the human-derived strain (Figure 8). However, the human strain was fully competent to colonize all animals persistently.

\section{Discussion}

In order to curb the high numbers of human Campylobacter infections, zoonotic transmission to humans needs to be reduced. Hence, the identification of specific groups of strains or strain properties which are associated with the colonization of humans or specific animals may help to provide targets for such measures. In the present study, an in-depth genetic and phenotypic characterization of a diverse array of Campylobacter strains was initiated, including in particular closely genetically related strains of ST-21 isolated from diverse habitats and isolation sources.

From 2006 to 2010, Campylobacter isolates were collected in the framework of the FBI-Zoo network from humans, diverse animals and food sources in Germany. The complete collection of 473 strains was subjected to MLST analysis, making this one of the most comprehensive MLST analyses of Campylobacter from one country outside of the UK. Approximately one third of C. jejuni and one fourth of $C$. coli isolates belonged to five dominant 


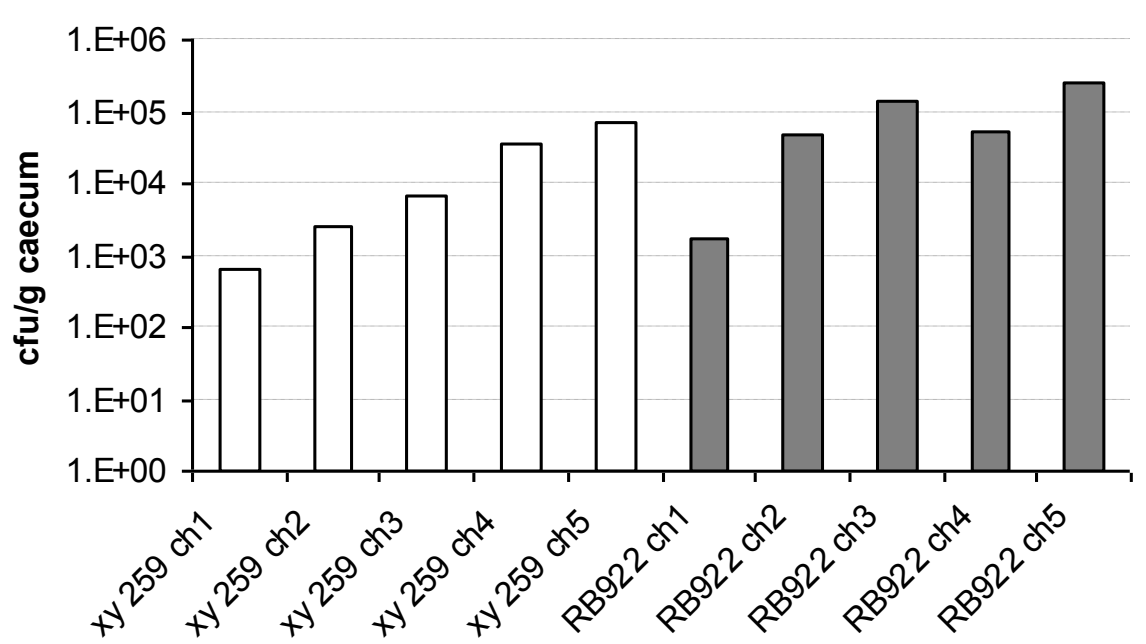

Figure 8 Chicken colonization of human-derived and chicken-derived C. jejuni ST-21 isolates. Real time PCR was performed on DNA isolated from caecal tissue of chickens after $14 \mathrm{~d}$ of infection (methods). Colony-forming units per $\mathrm{g}$ caecum were calculated from standardized bacterial DNA samples equivalent to a specific number of bacteria. White bars indicate chicks infected with human-derived strain xy259 (animals designated xy259 ch1 to ch5); grey bars indicate chicks inoculated with chicken-derived strain RB922 (animals RB922 ch1 to ch5).

STs, each representing at least 3\% of the isolates. Many dominant STs are also very prevalent in other geographical regions (e.g. C. jejuni STs 45, 48, 50, 21, 267; see also Additional File 2: Figure S2); as in other European regions, ST574, which is prevalent in New Zealand (http://PubMLST. org), was not identified in Germany. For C. jejuni, strains of all dominant STs were isolated from both humans and animals/food samples, indicating a broad host range and zoonotic potential. In contrast, approximately two thirds of C. jejuni strains were very diverse and represent rare STs, so that the low number of isolates per ST made it impossible to draw valid conclusions about their host association. These and previous data suggest that all dominant STs found in a variety of sources have a "generalist" phenotype, enabling them to colonize both humans and domestic animals. From these hosts, they can then be transmitted to humans either directly or via food. A previous whole genome-based study including 95 strains [16] suggested, that a host-specific Campylobacter subtype, or host-specific Campylobacter genes, may not exist, particularly in the dominant MLST sequence types, which are mainly derived from domestic sources that may have evolved under conditions of ample recent admixture [26]. This does not rule out that some of the rarer sequence types, such as isolates from wild animals which rarely mix with other niches, have irreversibly adapted to a single host species. Evidence for fixed host adaptation in a rare ST has been provided recently for sequence type ST-3704 [21,39], a C. jejuni variant from bank voles, which failed to colonize chickens. While strong evidence of admixture between $C$. coli and C. jejuni has been presented before [26], and is supported by the existence of alleles occurring in both C. jejuni and C. coli, the overall frequency of such shared alleles was very low in our collection (see also Additional File 1: Figure S1). Calculations of the standardized index of association and other tests for recombination were in agreement with previous studies demonstrating an important role of recombination in shaping the population structure of Campylobacter species. Notably, the $\mathrm{sI}_{\mathrm{A}}$ of $C$. coli was much lower than that of $C$. jejuni, suggesting more efficient exchange of alleles between $C$. coli strains than $C$. jejuni strains.

C. jejuni and C. coli have been shown to be versatile and diverse species, harbouring numerous genes related to host interactions or metabolism that are not present in all strains, or are subject to phase variation [20,30,40-42]. We have performed an extensive analysis of such genes in a large subset of our collection, and additional reference isolates. $91 \mathrm{C}$. jejuni strains were studied for the absence/presence and sequence variability of 18 genes with putative roles in phenotypes relevant to host interaction. These included genes coding for surface proteins, LOS, protein glycosylation and metabolic functions which have been suggested to play an important part in niche- or host-associated colonization abilities $[43,44,31,45]$.

The present data have not provided evidence that any of the genes tested was robustly associated with isolation source. By contrast, pathotyping profiles were in many cases closely correlated with phylogenetic grouping by sequence types, suggesting that Campylobacter have diversified their complements of in vivo essential genes. Apparently, the host interaction gene complement of dominant STs was selected to provide equal fitness advantages in both domestic ("food") animals and humans, permitting strain circulation between humans and domestic animals, 
making them "generalists". These generalist strains could then make use of different genetic features including reversible frame-shifting of contingency genes, intra-genomic and inter-genomic recombination to fine-tune their genetic and phenotypic capacities, which may benefit their survival in individual hosts or changing environments without preventing their generalist adaptation potential.

ST-21 is one of the most prevalent sequence types of C. jejuni present in a broad range of hosts $[14,15$, 17-19,46]. We have selected ST-21 to analyze the genetic and phenotypic diversity of $C$. jejuni within a group of closely related isolates, which appear to have generalist properties with respect to domestic hosts. Phenotypic characterization and metabolic profiling was performed for eight ST-21 isolates from different sources (two strains each from human, chicken, bovine and milk sources), and the genomes of five of these strains were sequenced. Metabolic profiling identified two characteristic biotypes within ST-21, with distinctive differences in their ability to metabolize certain carbon sources, including some dipeptides. Similar to the pathotyping results, none of these biotypes was associated with a specific isolation source, suggesting that both biotypes are compatible with a generalist lifestyle. In addition to differences in their metabolic capacities, the same strains also showed phenotypic diversity in their interaction with eukaryotic cells, independently of their isolation source. A further nine human C. jejuni strains from other rare and frequent STs (all isolated from humans) that were compared using the Biolog system showed metabolic fingerprints distinct from each other and also different from all ST-21 strains, revealing the metabolic fingerprint as a distinctive feature between and even within phylogenetic subtypes of the species. However, our study did not provide any evidence for a common metabolic fingerprint of human-derived strains.

The genome analysis of five ST-21 strains confirmed their high genetic relatedness, with long stretches of complete sequence identity and generally conserved synteny. However, pairwise and multiple comparisons of all sequences provided evidence of recombination that has caused the exchange of chromosome fragments of varying length, up to $\sim 15 \mathrm{kbp}$. These genome mosaicisms are reminiscent of the situation in the human gastric pathogen Helicobacter pylori, where genome comparisons of sequentially isolated strains from one single individual have yielded very similar mosaic patterns [47] to the ones observed here. In particular, the average length of imported fragments in the ST-21 genomes was $1,437 \mathrm{bp}$, between two and six times more than a previous estimate based on MLST data only [48], which could reflect the fact that MLST genes are under strong purifying selection [49]. The import length is about 3-4 times longer than the average length of imports calculated from $H$. pylori genome comparisons (394 bp, [47]) with the same analytical model.
Mutation and recombination were estimated to have occurred at similar rates, but recombination introduced 21.5 times more polymorphisms than mutation as it often substitutes several sites simultaneously [50]. Despite the strong evidence for recombination, the gene content in the five ST-21 genomes was very highly conserved. Only few strain-specific or unique genes were identified, most of which were part of phage gene clusters. These phage acquisitions represented almost the entire set of gene content differences between the sequenced ST-21 strains. Some phage genes were so far unknown; three of the phages (phage clusters 1, 2 and 7) were similar to previously described Campylobacter phages (CJIE1, CJIE3, CJIE4 families; $[23,22,51,52]$. The acquisition of some strain-specific genes appeared to be unique events and not related to the strain source or host. Yet, these closely related strains with identical MLST sequence types displayed substantial polymorphism ([20]; and Additional File 2: Table S7), largely caused by extensive inter-strain recombination and contingency genes. This corroborated earlier results from microarray comparisons which claimed that $C$. jejuni strains possess a high level of genome diversity, even within a single sequence type [53,54]. Extended testing for variant alleles of certain candidate genes in other dominant or rare STs or in specific groups of strains from specific host or source did not reveal any fixed host relation. Some of these variants may indicate a pressure for phenotypic diversification, for example due to bacteriophage resistance, or might still affect fitness in specific hosts or under certain colonization conditions. We propose that the observed microdiversity may allow these bacteria to flexibly and reversibly adapt to diverse habitats and to propagate their generalist phenotypes. Experimental infection of two genomesequenced ST-21 strains in chickens revealed that a ST-21 strain isolated from a human was fully competent to colonize chickens, albeit to a slightly lower density than a chicken isolate inoculated in a parallel experiment. This suggests that no general colonization barrier for humanderived ST-21 strains exists in chicken. Extensive genetic analyses of 95 whole genomes of $C$. coli and C. jejuni (43 C. jejuni genomes) have recently revealed that genetically distantly related isolates show considerable variability in gene content [16]. The authors of this study, however, did not find evidence of statistical association between gene content and type of host. Additional work suggested that the observed genetic diversity between $C$. jejuni isolates were instead closely associated with phylogenetic origin of the strains [34]. In a recent study, a human C. jejuni strain was inoculated in parallel into outbred chickens and inbred genetically modified mice [55], resulting in a much lower variation in the output pool from the mice compared to that of chickens. In a second experimental system of strain diversification, one specific $C$. jejuni variant in a contingency gene was strongly enriched by serial mouse passage 
[56]. This may suggest that, in contrast to a host population of low genetic variability such as inbred mice, Campylobacter requires genetic flexibility in a host population consisting of phenotypically and immunologically diverse individuals, including factors such as resident microbiota and bacteriophage abundance. Given these findings, it seems plausible that abundant Campylobacter types profit in many different ways from their established genome flexibility, even within a single host species.

\section{Conclusions}

While our findings do not rule out the existence of phenotypic and genotypic determinants of Campylobacter tissue tropism and host specificity, our results from ST-21 genomic and phenotypic comparisons rather support a view where all ST-21 strains are characterized by a generalist genome, phenotype and lifestyle, which support their ability to colonize both humans and food animals. The same might be true for other dominant $C$. jejuni STs and should be investigated further. This view is also supported by an extended MLST study of Campylobacter isolates in the UK [57]. These frequent types may possess a clear fitness advantage under diverse conditions. We propose that future efforts should be directed towards defining the molecular determinants of this phenotypic flexibility and generalist capacity, which might be useful targets for interventions into the transmission cycle, and hence ultimately reduce Campylobacter-associated diseases. For their high numbers of human infections caused world wide, and their very broad transmission capacities, the dominant Campylobacter STs deserve intensive attention. If the hypothesis of generalist and specialist strain types can be confirmed in larger Campylobacter strain collections, it would suggest to study host-specificity or the predictive value of molecular subtyping methods separately for the dominant and the rare ST groups.

\section{Methods}

\section{Bacterial strains and culture conditions}

The 473 recent strains (2006 to 2010) from the FBI-Zoo collection were collected in different regions in Germany (Additional File 1: Table S1) and from different hosts and food sources by members of the FBI-Zoo research network http://www.fbi-zoo.net. Additional reference strains of different sequence types were included in some of the analyses, which increased the number of analyzed strains to 492 (Additional File 1: Table S1). In some instances, Preston broth (Oxoid, Wesel, Germany) was used for bacterial enrichment, and Karmali or Skirrow Agar (Oxoid) for primary cultivation of Campylobacter spp.. All Campylobacter strains were routinely grown at $37^{\circ} \mathrm{C}$ or $42^{\circ} \mathrm{C}$ under microaerobic conditions $\left(10 \% \mathrm{CO}_{2}, 5 \% \mathrm{O}_{2}, 85 \% \mathrm{~N}_{2}\right)$ in vented jars on blood agar plates (Blood Agar Base II; Oxoid), supplemented with $10 \%$ defibrinated horse blood
(Oxoid) and antibiotics (10 mg/liter vancomycin, 2,500 U/ liter polymyxin B, $5 \mathrm{mg} /$ liter trimethoprim, $4 \mathrm{mg} / \mathrm{liter}$ amphotericin B), or on thioglycollate agar (Oxoid). For DNA preparations, coincubation assays, lysates preparations and phenotypic arrays bacteria were grown on plates for approximately $24 \mathrm{~h}$ before harvest. For some applications, bacteria were incubated in air-tight jars using an atmosphere generated by Oxoid CampyGen or Merck Anaerocult C sachet (Merck, Darmstadt, Germany) catalysts.

\section{Cell types, cell culture conditions and cell coincubation with Campylobacter strains}

Different cell lines were used for cell coincubation and adherence assays. The human colon adenocarcinoma cell line Caco-2 (ACC 57 and 169, German Collection of Microorganisms and Cell Cultures Braunschweig) was grown in Dulbecco's MEM supplemented with $10 \%[\mathrm{v} / \mathrm{v}]$ fetal bovine serum (FBS). The porcine intestinal epithelial cell line IPEC-J2 [58] was grown in Dulbecco's MEM and Ham's F-12 (1:1 mixture) supplemented with 5\% [v/v] FBS, and the HD-11 chicken macrophage-like cell line was maintained in IMDM + GlutaMAX-I (Gibco, Darmstadt, Germany) supplemented with 10\% [v/v] FBS. Caco2, HD11 and IPEC-J2 cell lines stably transfected with the firefly luciferase gene were generated by $\mathrm{K}$. Tedin and continuously cultured in the presence of puromycin $(5 \mathrm{~g} / \mathrm{L})$. All cell lines were routinely kept at $37^{\circ} \mathrm{C}$ in a $5 \% \mathrm{CO}_{2}$ humidified atmosphere.

For the cell adherence assays, Caco-2, IPEC-J2 and HD11 cells were seeded at $2 \times 10^{4}$ cells per well in a 96 well plate and grown to near confluency. The cell medium was replaced prior to the coincubation, $1 \mathrm{~h}$ before the addition of bacterial cells. The bacterial strains were prepared as follows: bacteria were harvested from plates with a sterile cotton swab and resuspended in $2 \mathrm{ml}$ sterile cold PBS, after that all steps were performed on ice. $2 \times 10^{8}$ bacteria were washed 3 times $\left(5 \mathrm{~min}, 5,000 \times \mathrm{g}, 4^{\circ} \mathrm{C}\right.$ ) in PBS, gently resuspended in $450 \mu \mathrm{l} \mathrm{PBS}$ and surface-biotinylated by adding $125 \mu \mathrm{g}$ EZ-link-TM-Sulfo-NHS-LC-Biotin (Thermo Scientific, Rockford, IL, USA). The subsequent incubation took place at RT in the dark for $50 \mathrm{~min}$. Afterwards the bacteria were washed 3 times and resuspended in $200 \mu \mathrm{l}$ cell culture medium. Before adding the bacteria to the cells, the bacteria were warmed to $37^{\circ} \mathrm{C}$, added to the cells to an MOI of 50 and 200 bacteria per cell, and centrifuged for $5 \mathrm{~min}$ at $200 \times \mathrm{g}$ to ensure bacteria-host cell contact. The subsequent coincubation lasted $1 \mathrm{~h}$, before $2 \times$ washes with PBS were performed to remove the non-adherent bacteria. The following fixation step of the cells was initiated by removing the medium and by adding $100 \mu \mathrm{l}$ of $2 \%$ paraformaldehyde (in $100 \mathrm{mM}$ potassium phosphate buffer, $\mathrm{pH}$ 7.0) for $2 \mathrm{~h}$ at RT. After fixation, the wells were washed 3 times with PBS $+0.1 \%$ 
glycine and incubated in a blocking solution (PBS, pH 7.0, $10 \% \mathrm{FBS}$ ) for $1 \mathrm{~h}$, followed by 5 times washing (PBS, pH 7.0, $0.05 \%[\mathrm{v} / \mathrm{v}]$ Tween 20). The cell layers together with adherent bacteria were incubated for $1 \mathrm{~h}$ with neutravidinHRP-conjugate (in PBS pH $=7.0$ with $10 \% \mathrm{FBS}[\mathrm{v} / \mathrm{v}]$, (1:5000); Perbio Science, Germany). After 7 times washing (PBS, pH 7.0, 0.05\% [v/v] Tween 20), the wells were incubated for $30 \mathrm{~min}$ with $100 \mu \mathrm{l}$ TMB substrate (Perbio Science, Germany). The resulting colour reaction was stopped by adding $50 \mu \mathrm{l} 1 \mathrm{M}$ phosphoric acid and measured at $450 \mathrm{~nm}$ (reference filter $540 \mathrm{~nm}$ ) in a microplate reader.

For the cytokine release assay (human IL-8), Caco-2 and Hela cells were seeded at $1.5 \times 10^{5}$ cells in $1 \mathrm{ml}$ of medium per well in a 24 well plate and incubated, until a confluency of $80 \%$ was reached (app. $24 \mathrm{~h}$ ). The medium was replaced before the addition of bacteria. The cell monolayers were infected with $C$. jejuni strains at an MOI of 10, centrifuged $10 \mathrm{~min}$ at $300 \times \mathrm{g}$ and coincubated for $4 \mathrm{~h}$, before the supernatants were harvested. After a centrifugation step to remove the bacteria $(9,000 \times \mathrm{g}, 2 \mathrm{~min})$ the supernatants were stored at $-20^{\circ} \mathrm{C}$. Analysis of the cell supernatants for IL-8 protein secretion was performed using the BD OptEIA human IL-8 Kit (BD Biosciences, Heidelberg, Germany) according to the manufacturer's instructions.

For the NF- $\kappa \mathrm{B}$ reporter assay, the stably transfected cell lines CaCo2, IPEC-J2 and HD-11, containing a NF$\kappa \mathrm{B}$-Luc reporter fusion, were seeded at $2 \times 10^{4}$ cells in $200 \mu \mathrm{l}$ medium per well in a 96 well plate and incubated for 24 hours. The medium was replaced before the addition of bacteria with the medium $(100 \mu \mathrm{l}$ per well $)$ in the absence of antibiotics. The cell monolayers were infected with C. jejuni strains at an MOI of 50 in triplicates, centrifuged $5 \mathrm{~min}$ at $300 \times \mathrm{g}$ to sediment the bacteria, and coincubated for $1 \mathrm{~h}$. After the coincubation, $50 \mu \mathrm{l}$ of Steady-Glo ${ }^{\circledR}$ Luciferase Assay Substrate (Promega Inc., Madison, WI, U.S.A.) was added to each well and incubated for $10 \mathrm{~min}$ to lyse bacteria and start the enzymatic reaction. The luminescence was then measured with a Wallac 1420 Victor3 V multilabel counter instrument (PerkinElmer, Waltham MA, U.S.A.).

\section{Generation of antisera}

The C. jejuni antiserum 5699 was raised in rabbits against a mixture of six phylogenetically diverse strains, which were first fixed in paraformaldehyde, washed, and then administered to the animals by intradermal injection. The chicken antiserum M3 (generously provided by Bernd Kaspers) was obtained from a laying hen which was naturally infected with a $C$. jejuni strain (M3a, see Additional File 1: Table S1).

\section{Measurement of cellular ATP content}

As an equivalent of intrabacterial energy harvest of each strain at specific culture conditions, intracellular ATP of different $C$. jejuni strains was measured. Bacteria were prepared as suspensions with O.D. 600 values of $0.3\left(10^{8}\right.$ cells/ $\mathrm{ml}$ ) in RPMI 1640 defined cell culture medium at $\mathrm{pH} 7.4$ (RPMI 1640 medium buffered with 20 mM HEPES; Invitrogen Inc., Darmstadt, Germany) Cells were taken directly from freshly grown plates $\left(24 \mathrm{~h}\right.$ growth, at $\left.37^{\circ} \mathrm{C}\right)$ and resuspended gently in liquid medium without prior washing. The bacteria were then incubated for $30 \mathrm{~min}$ at $37^{\circ} \mathrm{C}$ before starting the ATP assay. For determining ATP contents of the cells, BacTiter-Glo reagent (an ATPdependent luciferase-luciferin reagent mixture; Promega Inc., Madison, WI) was added directly to the live bacterial suspensions at a ratio of 1:1 after the incubation time. The suspensions were incubated at $37^{\circ} \mathrm{C}$ for $5 \mathrm{~min}$ to lyse the bacteria and to initiate the enzymatic reaction. The emission of photons was then measured with a Wallac 1420 Victor3 V multilabel counter instrument (PerkinElmer) in luminescence mode. All experiments were performed at least two times on separate days in duplicate measurements. Values were collected and further processed in MS Excel, calculating the level of luminescence (as relative luminescence units). In the results, one representative experiment is shown.

\section{DNA and protein methods}

Genomic DNA of bacteria was extracted using the QIAamp DNA purification kit (Qiagen) according to the manufacturer's instructions. PCRs were performed with standard methods using Taq polymerase (Roche, Basel, Switzerland). PCR products prepared for Sanger sequencing were purified using the PCR purification kit (Qiagen, Hilden, Germany) according to the manufacturer's instructions before sequencing.

For the preparation of bacterial lysates, bacteria were grown for $24 \mathrm{~h}$ at $37^{\circ} \mathrm{C}$ or $42^{\circ} \mathrm{C}$ in a microaerobic atmosphere, harvested with sterile cotton swabs and resuspended in ice-cold $0.9 \% \mathrm{NaCl}$. The bacterial cells were sonicated three times $1 \mathrm{~min}$ with an ultrasonic device (Branson Sonic Power Company, Danbury, U.S.A.) at $4{ }^{\circ} \mathrm{C}$ and at power level $5(80-100 \mathrm{~W})$. The amount of proteins in the lysates was analyzed using the BCA Protein Assay (Pierce, Rockford IL, USA). The proteins were separated on $11.5 \%$ SDS-polyacrylamide gels. Western immunoblotting was performed according to standard methods using the chicken antiserum M3 or our specific customary $C$. jejuni-mix antiserum 5699. Immuno-reactive bands were visualized with Super Signal West Pico chemiluminescent substrate (Pierce, Thermo Scientific, Bonn, Germany) on ECL hyperfilm (GE Healthcare, Piscataway NJ, U.S.A.). 
Table 2 Oligonucleotide primers used for the amplification of $C$. jejuni genes

\begin{tabular}{|c|c|c|c|c|}
\hline Gene & Primers & Sequence $\left(5^{\prime}-3^{\prime}\right)$ & $T_{m}{ }^{a}$ & Reference \\
\hline$\overline{C j 0977}$ & $\begin{array}{l}\text { Cj0977_F1 } \\
\text { Cj0977_R1 }\end{array}$ & $\begin{array}{l}\text { TGAAGCACCCAAAAGAGTTTATATACG } \\
\text { TITCTGGATGTTTGTAAATGAAAG }\end{array}$ & 59 & This study \\
\hline$\overline{f s p A 1}$ & $\begin{array}{l}\text { CjfspA1_F1 } \\
\text { CjfspA1_R1 }\end{array}$ & $\begin{array}{l}\text { ATGTCGATTTAGTGTAATATATAT } \\
\text { TAATCAGGCTTGGTGGCTTGG }\end{array}$ & 53 & This study \\
\hline fspA2 & $\begin{array}{l}\text { CjfspA2_F1 } \\
\text { CjfspA2-RT04 }\end{array}$ & $\begin{array}{l}\text { AAACCGATAACAATATAAATTAATTTAAAAAG } \\
\text { AAGCCTCTAATGCGGGATTT }\end{array}$ & 53 & This study [33] \\
\hline$\overline{C j f l a A}$ & $\begin{array}{l}\text { Fla4F } \\
\text { Fla1728R }\end{array}$ & $\begin{array}{l}\text { GGATTTCGTATTAACACAAATGGTGC } \\
\text { CTGTAGTAATCTTAAAACATTITG }\end{array}$ & 55 & [63] \\
\hline FlaC & $\begin{array}{l}\text { CjflaC_F1 } \\
\text { CjflaC_R1 }\end{array}$ & $\begin{array}{l}\text { CTAATACCATAATTGAACTCC } \\
\text { TTCTACTATACCTTGATCAAAAAG }\end{array}$ & 51 & This study \\
\hline neuC1 & $\begin{array}{l}\text { CjneuC1_F1 } \\
\text { CjneuC1_R1 }\end{array}$ & $\begin{array}{l}\text { GGTGATAGAGTGGAGCCTITAGCTG } \\
\text { GTCAGTTCTACCATCTTGTCTTGAACC }\end{array}$ & 49 & [32] \\
\hline cadF & $\begin{array}{l}\text { CjcadF_F2B } \\
\text { CjcadF_R1B }\end{array}$ & $\begin{array}{l}\text { TTGAAGGTAATTAAGATATG } \\
\text { CTAATACCTAAAGTTGAAAC }\end{array}$ & 45 & [64] \\
\hline$\overline{c d t B}$ & $\begin{array}{l}\text { CjcdtB_F } \\
\text { CjcdtB_R }\end{array}$ & $\begin{array}{l}\text { GTTGGCACTTGGAATTTGCAAGGC } \\
\text { GTTAAAATCCCCTGCTATCAACCA }\end{array}$ & 60 & [65] \\
\hline$\overline{c g t B}$ & $\begin{array}{l}\text { DL39 } \\
\text { cgtBrev }\end{array}$ & $\begin{array}{l}\text { TTAAGAGCAAGATATGAAGGTG } \\
\text { GCACATAGAGAACGCTACAA }\end{array}$ & 53 & [66] \\
\hline$\overline{c i a B}$ & $\begin{array}{l}\text { CjCiaB-F } \\
\text { CjCiaB-R }\end{array}$ & $\begin{array}{l}\text { CTATGCTAGCCATACTTAGGC } \\
\text { GCCCGCCTTAGAACTTAC }\end{array}$ & 51 & [67] \\
\hline$\overline{p g l B}$ & $\begin{array}{l}\mathrm{pglBf} \\
\mathrm{pglBr}\end{array}$ & $\begin{array}{l}\text { ACTTGGTGGGATTATGGTTATCCTG } \\
\text { TCACGAGTITITGGTGTATCGATIT }\end{array}$ & 60 & {$[68]$} \\
\hline ggt & $\begin{array}{l}\text { IF50 } \\
\text { IF100 }\end{array}$ & $\begin{array}{l}\text { GGG TAA ATA AGA AGT TAG AAT TC } \\
\text { CTT GAT AAA GGC GGA AAT GCC }\end{array}$ & 55 & [69] \\
\hline$g g t$ & $\begin{array}{l}\text { Cjggt_fw1 } \\
\text { Cjggt_rv1 }\end{array}$ & $\begin{array}{l}\text { TITAAGCCATATCCGCTGCT } \\
\text { AGCTGGAGTACCAGGAA }\end{array}$ & 49 & {$[12]$} \\
\hline$g g t$ & $\begin{array}{l}\text { Cjggt_fw2 } \\
\text { Cjggt_rv1 }\end{array}$ & $\begin{array}{l}\text { AAATAGCTTGGTATTGTGCT } \\
\text { AGCTGGAGTACCAGGAA }\end{array}$ & 49 & This study \\
\hline ansB perip. & $\begin{array}{l}\text { ansB_fw3_deg } \\
\text { ansB_rv1 }\end{array}$ & $\begin{array}{l}\text { TWTYTATAGGAGYATGTA } \\
\text { CAA ATA AAG CTT TTG CAG C }\end{array}$ & 51 & This study \\
\hline $\begin{array}{l}\text { ans } B \\
\text { secr. }\end{array}$ & $\begin{array}{l}\text { ansB_fw2 } \\
\text { ansB_rv1 }\end{array}$ & $\begin{array}{l}\text { CAA AAT AAG GGG AGA ATT GTG } \\
\text { CAA ATA AAG CTT TTG CAG C }\end{array}$ & 49 & This study \\
\hline$f \mid p A$ & $\begin{array}{l}\text { CjflpA_fw1 } \\
\text { CjflpA_rv1 }\end{array}$ & $\begin{array}{l}\text { CTGGTACTAAGTATCGTTATA } \\
\text { AAGGAAGCTTGAGCTCGTA }\end{array}$ & 51 & This study \\
\hline$t \mid p 7$ & $\begin{array}{l}\text { tlp7-F01 } \\
\text { tlp7-R01 }\end{array}$ & $\begin{array}{l}\text { AGGTTTCTGCTGCAATTTITGTGGTG } \\
\text { AGCAAGTTCTCCAAGTTCATTGCCA }\end{array}$ & 60 & [18] \\
\hline$\overline{d m s} A$ & $\begin{array}{l}\text { dmsA_F } \\
\text { dmsA_R }\end{array}$ & $\begin{array}{l}\text { GATAGGGCATTGCGATGAGT } \\
\text { CTTGCTAGCCCAATCAGGAG }\end{array}$ & 55 & [12] \\
\hline Cj1585 & $\begin{array}{l}\text { Cj1585c_F } \\
\text { Cj1585c_R }\end{array}$ & $\begin{array}{l}\text { TGTTGTGGGTTTGCTGGATA } \\
\text { TTGCTTCACTGCATTCATCC }\end{array}$ & 53 & [12] \\
\hline$\overline{c a p A}$ & $\begin{array}{l}\text { CjcapA_F } \\
\text { CjcapA_R }\end{array}$ & $\begin{array}{l}\text { TGAATCGAAGTGGAAAAATAGAAG } \\
\text { CCCATITITGATCTTCATAACCT }\end{array}$ & 60 & {$[70]$} \\
\hline fucP & $\begin{array}{l}\text { CjfucP_F1 } \\
\text { CjfucP_R1 }\end{array}$ & $\begin{array}{l}\text { CTTCATATTAGCCAGCATGA } \\
\text { CCATATTAGCTACCAATGCA }\end{array}$ & 51 & This study \\
\hline
\end{tabular}

annealing temperature in ${ }^{\circ} \mathrm{Celsius} ;{ }^{\mathrm{b}}$ perip. $=$ periplasmic; secr. $=$ secreted

Molecular typing and pathotyping methods

492 C. jejuni and C. coli strains from our collection (473 of which were isolates collected between 2006 and 2010, the others were collected earlier and included some reference strains) comprising strains from different sources in Germany were MLST-typed as described in Dingle et al., 2005 [25]. Briefly, genomic DNA was amplified with primer pairs for seven housekeeping genes, $\operatorname{ssp} A, g \ln A, g l t A$, $g l y A, p g m A, t k t$, and $u n c A$. The PCR-products were purified as described above and sequenced in both orientations using the Sanger method. The MLST data were collected in Seqsphere (RIDOM GmbH, Wuerzburg, Germany; http://www.ridom.de/seqsphere/) and Bionumerics (Applied Maths, Sint Martens-Latem, Belgium). Phylogenetic relationships between the STs were calculated by MLST-based cluster analysis in Bionumerics. 
Minimal Spanning Trees were generated from the cluster analysis with 100 permutations (Bionumerics), using the seven MLST loci information.

Based on the MLST analysis, 91 C. jejuni strains with representative STs were chosen for the PCR-based pathotyping. The presence or absence of selected putative virulence genes was detected by PCR as described above and in the results. For some genes with previously described sequence diversity, such as $g g t$ and $a n s B$, multiple primer combinations were tested to exclude false-negative results and to ensure that the absence of the gene is not due to the sequence diversity. The genes and primers are listed in Table 2.

\section{Metabolic phenotyping using Biolog Phenotype Microarrays}

The bacteria were harvested from fresh plates after $24 \mathrm{~h}$ incubation at $37^{\circ} \mathrm{C}$ or $42^{\circ} \mathrm{C}$, resuspended in IF-0a medium (Biolog, Hayward, CA, U.S.A.) and adjusted to 16\% transmittance $\left(\mathrm{O} . \mathrm{D}_{600}=0.8\right)$. The cell suspension was mixed with a solution containing IF-0a, tetrazolium violet (Redox dye D), PM 1 additive and water according to the manufacturer's instructions (Biolog). $100 \mu \mathrm{l}$ of the final suspension was added to each well of the 96-well Biolog carbon utilization plate PM1. The PM1 panels were placed without lids into gas impermeable bags (Biolog) together with a Campy Gen Compact sachet (Oxoid) to generate a microaerobic atmosphere and sealed. All working steps were carried out under the laminar flow to ensure a sterile environment. The Biolog panels were incubated in the OmniLog instrument (Biolog) either at $37^{\circ} \mathrm{C}$ or $42^{\circ} \mathrm{C}$ for $30 \mathrm{~h}$. The utilization of different metabolites was recorded spectrophotometrically every 15 min over the whole incubation period, and evaluated with the OmniLog PM software (Kinetic Analysis). The area values (area under the kinetic curves) over time were used for comparison of substrate utilization between strains. All assays were repeated for at least three times on different days. Eight strains of ST-21 (xy259, A588, RB922, RB923, 6399, 7731, 04197, 04199) and nine, exclusively human-isolated, strains from other STs (xy898 [ST-50], R267 [ST-48], xy904 [ST-45], A396 [ST-267], 222 [ST-257], 02551 [ST-607], 02557 [ST-290], A412 [ST-51], A599 [ST-572]) were analyzed. Reproducibility of the assays was high, indicated by a low standard deviation of approximately $31 \%$, calculated for three independent biological replicate assays (evaluated only for constantly positive area values $>800$, since area values below 800 were evaluated not to be reliably positive). False-positive results for four pentose sugars, D-xylose, $\mathrm{L}$-arabinose, $\mathrm{D}$-ribose and L-lyxose, which were due to the sensitivity of the redox dye alone, as confirmed by incubating Biolog plates in the absence of bacteria, were excluded from the analysis. These false positive results have also been described before by others [59]. No other false positive results for saccharides were noted.

\section{Campylobacter whole genome sequencing and sequence analysis}

Whole genomic DNA for 454 sequencing was isolated using Qiagen Genomic tip 100/G columns and the Genomic DNA Buffer Set (Qiagen). High quality genomic DNA of $C$. jejuni was then sheared according to a reproducible method by nebulization, quality-controlled on an Agilent bioanalyzer chip (DNA Chip7500, Agilent, Santa Clara, CA, U.S.A.), end-polished with T4 DNA polymerase and T4 polynucleotide kinase (New England Biolabs, Beverly MA, U.S.A.) [47]. DNA fragments were then subjected to bead coating and 454 sequencing in a Roche 454 sequencer, using FLX Titanium (Roche) chemistry according to the manufacturer's instructions.

Subsequent to the pyrosequencing process, the Roche Assembler software was used for assembling the primary reads into contigs. Between 37 and 156 contigs were obtained for the five whole genome sequences (xy259: 68 contigs, estimated genome size: 1,7 Mbp; RB922; 156 contigs, estimated genome size $1.7 \mathrm{Mbp}$; 6399: 43 contigs, estimated genome size 1.5 Mbp; 04197: 83 contigs, estimated genome size 1.7 Mbp; 04199: 71 contigs, estimated genome size $1.8 \mathrm{Mbp}$ ). Further statistics for the sequencing process and additional quality controls are available upon request. The draft genome sequences are available in the ENA EMBL-Bank database with accession numbers CAFR01000001-68, CAFS01000001-156, CAFT0100000143, CAFU01000001-83, CAFV01000001-71. Further, the genomes were annotated in the Kodon software (Applied Maths, Sint Martens-Latem, Belgium) using several publicly available complete $C$. jejuni genome sequences, and the contigs of the draft sequences were then ordered 1) by aligning all five draft sequences to each other, and 2) by aligning all five genome sequences using the finished genome of C. jejuni 11168 [20] as a scaffold. Whole genome alignments were generated within the Kodon, GeneDoc (http://www.psc.edu/biomed/genedoc) and MAUVE [60] softwares. All pairs of genomes (reference genome was 04199 for all pairwise comparisons) were analyzed using the Hidden Markov Model implemented in ClonalFrame [61] which comprises two states: the "clonal" state in which only mutations separate the two genomes and the "recombined" state in which the polymorphism density is higher due to the import of unrelated DNA. This allowed to pinpoint the regions that had recombined, as well as to quantify the overall frequency and effect of recombination during the diversification of pairs of genomes. A similar approach was recently implemented by Kennemann et al [47]. 


\section{Chicken infection}

To evaluate the colonization ability of different $C$. jejuni strains, we infected three-weeks old specific-pathogen-free (SPF) white leghorn chicks (Lohmann Animal Health, Cuxhaven, Germany). Chicks were reared in cages and fed with a commercial diet devoid of antibiotics and provided with sterile drinking water ad libitum. The chicks (five animals per group) were inoculated by intraoesophagal gavage, twice on two subsequent days, each time with a $0.5 \mathrm{ml}$ suspension containing $5 \times 10^{7} \mathrm{cfu} / \mathrm{ml}$ of a $C$. jejuni human- (xy259) or chicken-derived (RB922) strain, resuspended in Brain Heart Infusion (BHI, Oxoid) broth. One day prior to the infection, cloacal swabs were taken to confirm by plating and by genus- and species-specific PCR that the chickens were Campylobacter-free. On days 2, 3, 6, 9 and 13 after the second inoculation, cloacal swabs were again taken for continuous monitoring of the colonization levels. The swabs were first streaked onto Columbia blood agar plates supplemented with selective antibiotics (see above) and after that used for the extraction of chromosomal DNA according to the QiaAmp Tissue DNA spin kit protocol. The presence of $C$. jejuni strains in the infected animals was confirmed for the swab DNAs and the cultured bacteria by PCR with specific Campylobacter genus primers, based on the $16 \mathrm{~S}$ ribosomal RNA gene sequence [62], and by primers specific for several C. jejuni genes. On day 15 after the second inoculation, the chickens were sacrificed. Caeca were sampled from all animals for DNA and RNA isolation. DNA was prepared from equivalent pieces of the caecal tip tissue for all animals using the QiaAmp Tissue DNA Spin kit (Qiagen). Colonization levels in the caecum were quantitatively evaluated for all animals using Real Time PCR on equal amounts of DNA prepared from caecal total tissue. All animal experiments were performed according to German legal requirements with approval by the federal government of Berlin permit from SoGeLa no. G 0210/09.

\section{RNA preparation}

An inoculum of the Campylobacter strains was prepared from bacteria grown for less than $24 \mathrm{~h}$ on Columbia blood agar plates. The bacteria were inoculated at an initial $\mathrm{O}$. D. 600 of approximately 0.08 into liquid medium (BHI Broth) in the presence of $5 \%$ horse serum (Oxoid). Bacteria were grown in liquid medium overnight, up to an $\mathrm{O}$. $\mathrm{D}_{.600}$ of 0.4 to 0.6 . Bacteria were then harvested by centrifugation $(21.000 \times \mathrm{g}$ for $2 \mathrm{~min}$, room temperature), bacterial pellets flash frozen in liquid nitrogen and stored at $-80^{\circ}$ C. For RNA preparation, bacterial pellets were resuspended in Qiagen RNeasy lysis buffer containing b-mercaptoethanol and lysed in a beadbeater machine (Fastprep, Bio101 Thermo Scientific, Bonn, Germany) for $45 \mathrm{~s}$. The RNA was further purified from the lysates using the Qiagen RNeasy protocol. Total RNA was quantitated in a
Nanodrop 1000 device (Thermo Scientific, Bonn, Germany) and equal amounts of each sample subjected to DNAse I treatment (Roche). Residual content of DNA was determined by PCR using Campylobacter genus-specific 16S rDNA primers (Table 2), and, if necessary, the residual DNA was removed by a second DNAseI treatment and subsequent RNeasy column purification. cDNA was prepared from equivalent amounts $(1 \mu \mathrm{g})$ of total RNA using Superscript III reverse transcriptase (Invitrogen Inc.) and using random hexamer primers according to the manufacturer's instructions. PCR or RT PCR using gene-specific primers (Table 2) was then performed on equal amounts of cDNA $(0.5$ to $2.5 \mu \mathrm{l})$ and normalized to a $16 \mathrm{~S}$ rDNA RT PCR control reaction.

\section{Real time PCR (TaqMan)}

The RT-PCR was performed using SYBR Green (Qiagen). Reactions were carried out on a Bio-Rad cycler (Abi TaqMan 7000 [ABI Applied Biosystems by Life Technologies, Darmstadt, Germany] and BioRad C1000/CFX96 combined system [BioRad, Hercules, CA, U.S.A:]). Primers targeted to the $p g l B$ gene (Table 2) were used to amplify sequences specific for $C$. jejuni. Cycling conditions were as follows: denaturation for $10 \mathrm{~min}$ at $95^{\circ} \mathrm{C}$, amplification for 40 cycles at $95^{\circ} \mathrm{C}$ for $30 \mathrm{~s}, 60^{\circ} \mathrm{C}$ for $15 \mathrm{~s}$, and at $72^{\circ} \mathrm{C}$ for $30 \mathrm{~s}$. For quantification of DNA amounts, a serial standard was prepared from a purified PCR product of the $C$. jejuni pglB gene (strain xy259). Final concentrations of the standard were $10 \mathrm{pg}, 1 \mathrm{pg}, 0.1 \mathrm{pg}, 0.01 \mathrm{pg}$ and $0.001 \mathrm{pg}$ of DNA. All standard probes were also prepared in a second serial dilution mixed with mouse caecum DNA at a final concentration of $100 \mathrm{ng}$ per $\mu \mathrm{l}$ in each sample (spiked samples). The same concentration of total DNA was used in the final reactions for all DNAs prepared from infected chicken caeca. Each reaction was performed in duplicate.

\section{Additional material}

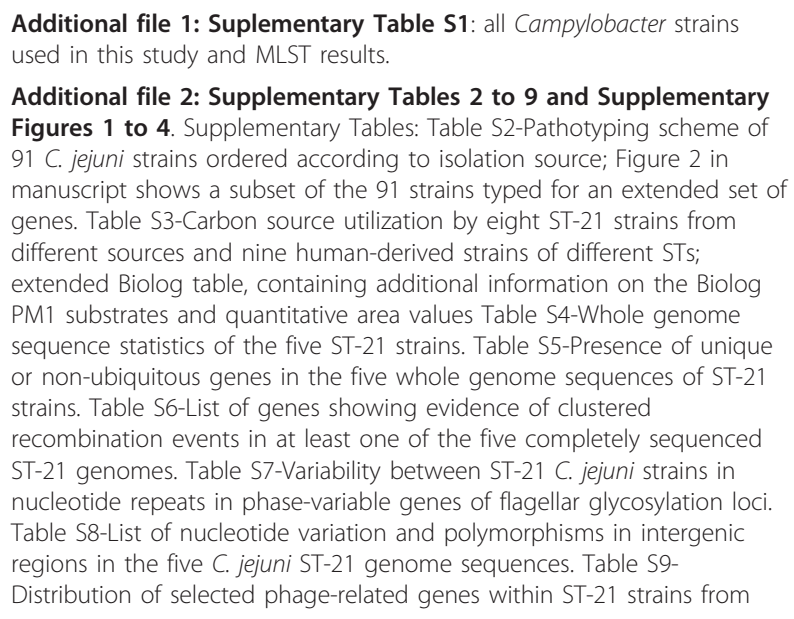


different sources. Supplementary Figures: Figure S1-Minimal spanning tree of all FBI-Zoo Campylobacter isolates colour-coded according to their assignment to the two Campylobacter species C. jejuni and C. coli. Figure S2-Minimal spanning tree of all FBI-Zoo Campylobacter isolates in the context of the PubMLST database (http://PubMLST.org). Figure S3-Gene categories (COG) in recombined stretches of sequence in ST-21 C. jejuni genome sequences. Genes in recombined stretches of the sequence of five ST-21 strains were grouped into COG categories indicating functional assignments; the graphic representation shows that no functional COG category is significantly overrepresented in the recombined gene clusters. Figure S4-Kodon snapshot from the alignment of five ST-2 strains with 04199 as reference; examples of microdiversity and clustered polymorphisms in a stretch of sequence compared between the complete genome sequences of five ST-21 C. jejuni strains are depicted.

Additional file 3: Supplementary Table S10: Statistical analysis of Campylobacter jejuni ST-21 genome comparisons using a Bayesian statistical model; comparative statistical values for the proportion of clonal sites, where mutations or recombination were found in each strain, are indicated; average length of recombined regions and amount of polymorphism brought in by recombination in each strain are also listed.

\section{Acknowledgements}

We acknowledge the German Ministry for Education and Research (BMBF) for funding in the framework of the FBI-Zoo center grant. The FBI-Zoo consortium, in particular members Helge Karch, Alexander Mellmann, Peter Valentin-Weigand, Bernd Kaspers, Alexandra von Altrock, Roswitha Merle, Lothar Kreienbrock, and Jürgen Heesemann, are acknowledged for providing strains freshly isolated from human patients and animals, and Thomas Weniger and Dag Harmsen for maintaining and improving the Seqsphere database infrastructure. Kerstin Stingl is gratefully acknowledged for providing fresh strains from food and food-associated outbreaks. We are very grateful to all members of the FBI-Zoo network for an excellent working atmosphere. Publication charges for this article were supported by the German Research Foundation in the framework of the program "Open Access Publishing". E.G. was supported in the framework of the International Research Training Grant IRTG1273 from the German Research Foundation.

\section{Author details}

'Institute for Medical Microbiology, Hannover Medical School, Hannover, Germany. ${ }^{2}$ Department of Statistics, University of Oxford, UK. ${ }^{3}$ Institute for Microbiology and Epizootics, Freie Universität Berlin, Germany. ${ }^{4}$ Federal Institute for Risk Assessment, Berlin, Germany. ${ }^{5}$ Institute for Biochemistry and Biotechnology, Technische Universität Braunschweig, Germany. ${ }^{6}$ Institute for Microbiology, University of Veterinary Medicine, Hannover, Germany. Institute of Food Hygiene, Freie Universität Berlin, Germany.

\section{Authors' contributions}

$\mathrm{DHI}, \mathrm{FK}, \mathrm{BB}, \mathrm{SW}, \mathrm{SM}, \mathrm{TJ}$, and PB performed experiments, KS, DS, MU and DHo contributed to methodology and data analysis, XD analyzed and discussed data, statistics and methodology, PG, GG, TA, TJ SM, LW LE, and KT provided materials, contributed to strain collections, experimental design and animal experiments, EG, SS, CJ designed and performed experiments, analyzed the data and wrote the paper. All authors read and approved the final manuscript.

Received: 7 September 2011 Accepted: 28 November 2011 Published: 28 November 2011

\section{References}

1. Humphrey T, O'Brien S, Madsen M: Campylobacters as zoonotic pathogens: a food production perspective. Int J Food Microbiol 2007, 117:237-257.

2. Snelling WJ, Matsuda M, Moore JE, Dooley JS: Campylobacter jejuni. Lett Appl Microbiol 2005, 41:297-302

3. Butzler JP: Campylobacter, from obscurity to celebrity. Clin Microbiol Infect 2004, 10:868-876.
4. Champion OL, Gaunt MW, Gundogdu O, Elmi A, Witney AA, Hinds J, Dorrell N, Wren BW: Comparative phylogenomics of the food-borne pathogen Campylobacter jejuni reveals genetic markers predictive of infection source. Proc Natl Acad Sci USA 2005, 102:16043-16048.

5. Devane ML, Nicol C, Ball A, Klena JD, Scholes P, Hudson JA, Baker MG, Gilpin BJ, Garrett N, Savill MG: The occurrence of Campylobacter subtypes in environmental reservoirs and potential transmission routes. J Appl Microbiol 2005, 98:980-990.

6. Lee MD, Newell DG: Campylobacter in poultry: filling an ecological niche. Avian Dis 2006, 50:1-9.

7. Stanley K, Jones K: Cattle and sheep farms as reservoirs of Campylobacter. J Appl Microbiol 2003, 94(Suppl):104S-113S.

8. Ogden ID, Dallas JF, MacRae M, Rotariu O, Reay KW, Leitch M, Thomson AP, Sheppard SK, Maiden M, Forbes KJ, Strachan NJ: Campylobacter excreted into the environment by animal sources: prevalence, concentration shed, and host association. Foodborne Pathog Dis 2009, 6:1161-1170.

9. Keestra AM, de Zoete MR, van Aubel RA, van Putten JP: Functional characterization of chicken TLR5 reveals species-specific recognition of flagellin. Mol Immunol 2008, 45:1298-1307.

10. de Zoete MR, Keestra AM, Roszczenko P, van Putten JP: Activation of human and chicken toll-like receptors by Campylobacter spp. Infect Immun 2010, 78:1229-1238.

11. Watson RO, Galan JE: Signal transduction in Campylobacter jejuni-induced cytokine production. Cell Microbiol 2005, 7:655-665.

12. Gonzalez M, Hakkinen M, Rautelin H, Hanninen ML: Bovine Campylobacter jejuni strains differ from human and chicken strains in an analysis of certain molecular genetic markers. Appl Environ Microbiol 2009, 75:1208-1210.

13. de Haan CP, Kivisto RI, Hakkinen M, Corander J, Hanninen ML: Multilocus sequence types of Finnish bovine Campylobacter jejuni isolates and their attribution to human infections. BMC Microbiol 2010, 10:200.

14. Suerbaum S, Lohrengel M, Sonnevend A, Ruberg F, Kist M: Allelic diversity and recombination in Campylobacter jejuni. J Bacteriol 2001, 183:2553-2559.

15. Dingle KE, Colles FM, Wareing DR, Ure R, Fox AJ, Bolton FE, Bootsma HJ, Willems RJ, Urwin R, Maiden MC: Multilocus sequence typing system for Campylobacter jejuni. J Clin Microbiol 2001, 39:14-23.

16. Lefebure T, Bitar PD, Suzuki H, Stanhope MJ: Evolutionary dynamics of complete Campylobacter pan-genomes and the bacterial species concept. Genome Biol Evol 2010, 2:646-55, Epub;\%2010 Aug 4.: 646-655.

17. Dingle KE, McCarthy ND, Cody AJ, Peto TE, Maiden MC: Extended sequence typing of Campylobacter spp., United Kingdom. Emerg Infect Dis 2008, 14:1620-1622

18. Zautner AE, Herrmann S, Corso J, Tareen AM, Alter T, Gross U: Epidemiological indication of different Campylobacter jejuni groups by metabolism-associated genetic markers. Appl Environ Microbiol 2011.

19. de Haan CP, Kivisto R, Hakkinen M, Rautelin H, Hanninen ML: Decreasing trend of overlapping multilocus sequence types between human and chicken Campylobacter jejuni isolates over a decade in Finland. Appl Environ Microbiol 2010, 76:5228-5236.

20. Parkhill J, Wren BW, Mungall K, Ketley JM, Churcher C, Basham D, Chillingworth T, Davies RM, Feltwell T, Holroyd S, Jagels K, Karlyshev AV, Moule S, Pallen MJ, Penn CW, Quail MA, Rajandream MA, Rutherford KM, van Vliet AH, Whitehead S, Barrell BG: The genome sequence of the foodborne pathogen Campylobacter jejuni reveals hypervariable sequences. Nature 2000, 403:665-668.

21. Hepworth PJ, Ashelford KE, Hinds J, Gould KA, Witney AA, Williams NJ, Leatherbarrow $H$, French NP, Birtles RJ, Mendonca C, Dorrel N, Wren BW Wigley P, Hall N, Winstanley C: Genomic variations define divergence of water/wildlife-associated Campylobacter jejuni niche specialists from common clonal complexes. Environ Microbiol 2011, 10-2920.

22. Parker CT, Quinones B, Miller WG, Horn ST, Mandrell RE: Comparative genomic analysis of Campylobacter jejuni strains reveals diversity due to genomic elements similar to those present in C. jejuni strain RM1221. J Clin Microbiol 2006, 44:4125-4135.

23. Fouts DE, Mongodin EF, Mandrell RE, Miller WG, Rasko DA, Ravel J, Brinkac LM, DeBoy RT, Parker CT, Daugherty SC, Dodson RJ, Durkin AS, Madupu R, Sullivan SA, Shetty JU, Ayodeji MA, Shvartsbeyn A, Schatz MC, Badger JH, Fraser CM, Nelson KE: Major structural differences and novel potential virulence mechanisms from the genomes of multiple Campylobacter species. PLoS Biol 2005, 3:e15. 
24. Poly F, Read T, Tribble DR, Baqar S, Lorenzo M, Guerry P: Genome sequence of a clinical isolate of Campylobacter jejuni from Thailand. Infect Immun 2007, 75:3425-3433.

25. Dingle KE, Colles FM, Falush D, Maiden MC: Sequence typing and comparison of population biology of Campylobacter coli and Campylobacter jejuni. J Clin Microbiol 2005, 43:340-347.

26. Sheppard SK, McCarthy ND, Falush D, Maiden MC: Convergence of Campylobacter species: implications for bacterial evolution. Science 2008, 320:237-239.

27. Wilson DJ, Gabriel E, Leatherbarrow AJ, Cheesbrough J, Gee S, Bolton E, Fox A, Hart CA, Diggle PJ, Fearnhead P: Rapid evolution and the importance of recombination to the gastroenteric pathogen Campylobacter jejuni. Mol Biol Evol 2009, 26:385-397.

28. Haubold B, Hudson RR: LIAN 3.0: detecting linkage disequilibrium in multilocus data. Linkage Analysis. Bioinformatics 2000, 16:847-848.

29. Flanagan RC, Neal-McKinney JM, Dhillon AS, Miller WG, Konkel ME: Examination of Campylobacter jejuni putative adhesins leads to the identification of a new protein, designated FlpA, required for chicken colonization. Infect Immun 2009, 77:2399-2407.

30. Hofreuter D, Tsai J, Watson RO, Novik V, Altman B, Benitez M, Clark C, Perbost C, Jarvie T, Du L, Galán JE: Unique features of a highly pathogenic Campylobacter jejuni strain. Infect Immun 2006, 74:4694-4707.

31. Hofreuter D, Novik V, Galan JE: Metabolic diversity in Campylobacter jejuni enhances specific tissue colonization. Cell Host Microbe 2008, 4:425-433.

32. Guerry P, Ewing CP, Hickey TE, Prendergast MM, Moran AP: Sialylation of lipooligosaccharide cores affects immunogenicity and serum resistance of Campylobacter jejuni. Infect Immun 2000, 68:6656-6662

33. Poly F, Ewing C, Goon S, Hickey TE, Rockabrand D, Majam G, Lee L, Phan J, Savarino NJ, Guerry P: Heterogeneity of a Campylobacter jejuni Protein That is Secreted through the Flagellar Filament. Infect Immun 2007, 75:3859-3867.

34. de Haan CP, Kivisto R, Hanninen ML: Association of Campylobacter jejuni Cj0859c gene (fspA) variants with different $C$. jejuni multilocus sequence types. Appl Environ Microbiol 2010, 76:6942-6943.

35. Muraoka WT, Zhang Q: Phenotypic and genotypic evidence for L-fucose utilization by Campylobacter jejuni. J Bacteriol 2011, 193:1065-1075

36. Stahl M, Friis LM, Nothaft H, Liu X, Li J, Szymanski CM, Stintzi A: L-Fucose utilization provides Campylobacter jejuni with a competitive advantage. Proc Natl Acad Sci USA 2011, 108:7194-7199.

37. Weingarten RA, Taveirne ME, Olson JW: The dual-functioning fumarate reductase is the sole succinate:quinone reductase in Campylobacter jejuni and is required for full host colonization. J Bacteriol 2009, 191:5293-5300.

38. Carrillo CD, Taboada E, Nash JH, Lanthier P, Kelly J, Lau PC, Verhulp R, Mykytczuk O, Sy J, Findlay WA, Amoako K, Gomis S, Willson P, Austin JW, Potter A, Babiuk L, Allan B, Szymanski CM: Genome-wide expression analyses of Campylobacter jejuni NCTC11168 reveals coordinate regulation of motility and virulence by flhA. J Biol Chem 2004, 279:20327-20338.

39. Williams NJ, Jones TR, Leatherbarrow HJ, Birtles RJ, Lahuerta-Marin A, Bennett M, Winstanley C: Isolation of a novel Campylobacter jejuni clone associated with the bank vole, Myodes glareolus. Appl Environ Microbiol 2010, 76:7318-7321.

40. Pearson BM, Gaskin DJ, Segers RP, Wells JM, Nuijten PJ, van Vliet AH: The complete genome sequence of Campylobacter jejuni strain 81116 (NCTC11828). J Bacteriol 2007, 189:8402-8403.

41. Hendrixson DR: Restoration of flagellar biosynthesis by varied mutational events in Campylobacter jejuni. Mol Microbiol 2008, 70:519-536.

42. Karlyshev AV, Champion OL, Churcher C, Brisson JR, Jarrell HC, Gilbert M, Brochu D, St Michael F, Li J, Wakarchuk WW, Goodhead I, Sanders M, Stevens K, White B, Parkhill J, Wren BW, Szymanski CM: Analysis of Campylobacter jejuni capsular loci reveals multiple mechanisms for the generation of structural diversity and the ability to form complex heptoses. Mol Microbiol 2005, 55:90-103.

43. Bacon DJ, Szymanski CM, Burr DH, Silver RP, Alm RA, Guerry P: A phasevariable capsule is involved in virulence of Campylobacter jejuni 81-176. Mol Microbiol 2001, 40:769-777.

44. Howard SL, Jagannathan A, Soo EC, Hui JP, Aubry AJ, Ahmed I, Karlyshev A, Kelly JF, Jones MA, Stevens MP, Logan SM, Wren BW: Campylobacter jejuni glycosylation island important in cell charge, legionaminic acid biosynthesis, and colonization of chickens. Infect Immun 2009, 77:2544-2556.

45. Guerry P, Szymanski CM, Prendergast MM, Hickey TE, Ewing CP, Pattarini DL, Moran AP: Phase variation of Campylobacter jejuni 81-176 lipooligosaccharide affects ganglioside mimicry and invasiveness in vitro. Infect Immun 2002, 70:787-793.

46. Sheppard SK, Dallas JF, Strachan NJ, MacRae M, McCarthy ND, Wilson DJ, Gormley FJ, Falush D, Ogden ID, Maiden MC, Forbes KJ: Campylobacter genotyping to determine the source of human infection. Clin Infect Dis 2009, 48:1072-1078.

47. Kennemann $L$, Didelot $X$, Aebischer $T$, Kuhn S, Drescher B, Droege M, Reinhardt R, Correa P, Meyer TF, Josenhans C, Falush D, Suerbaum S: Helicobacter pylori genome evolution during human infection. Proc Nat/ Acad Sci USA 2011, 108:5033-5038.

48. Fearnhead P, Smith NG, Barrigas M, Fox A, French N: Analysis of recombination in Campylobacter jejuni from MLST population data. J Mol Evol 2005, 61:333-340.

49. Didelot X, Maiden MC: Impact of recombination on bacterial evolution. Trends Microbiol 2010, 18:315-322.

50. Vos $\mathrm{M}$, Didelot $\mathrm{X}$ : A comparison of homologous recombination rates in bacteria and archaea. ISME J 2009, 3:199-208.

51. Clark CG, Ng LK: Sequence variability of Campylobacter temperate bacteriophages. BMC Microbiol 2008, 8:49

52. Gaasbeek EJ, Wagenaar JA, Guilhabert MR, van Putten JP, Parker $C T$, van der Wal FJ: Nucleases encoded by the integrated elements CJIE2 and CJIE4 inhibit natural transformation of Campylobacter jejuni. J Bacteriol 2010, 192:936-941.

53. Dorrell N, Hinchliffe SJ, Wren BW: Comparative phylogenomics of pathogenic bacteria by microarray analysis. Curr Opin Microbiol 2005, 8:620-626

54. Taboada EN, Mackinnon JM, Luebbert CC, Gannon VP, Nash JH, Rahn K: Comparative genomic assessment of Multi-Locus Sequence Typing: rapid accumulation of genomic heterogeneity among clonal isolates of Campylobacter jejuni. BMC Evol Biol 2008, 8:229.

55. Wilson DL, Rathinam VA, Qi W, Wick LM, Landgraf J, Bell JA, PlovanichJones A, Parrish J, Finley RL, Mansfield LS, Linz JE: Genetic diversity in Campylobacter jejuni is associated with differential colonization of broiler chickens and C57BL/6J IL10-deficient mice. Microbiology 2010, 156:2046-2057.

56. Jerome JP, Bell JA, Plovanich-Jones AE, Barrick JE, Brown CT, Mansfield LS: Standing genetic variation in contingency loci drives the rapid adaptation of Campylobacter jejuni to a novel host. PLOS ONE 2011, 6: e16399.

57. Sheppard SK, Colles FM, McCarthy ND, Strachan NJ, Ogden ID, Forbes KJ, Dallas JF, Maiden MC: Niche segregation and genetic structure of Campylobacter jejuni populations from wild and agricultural host species. Mol Ecol 2011, 10-294X.

58. Schierack P, Nordhoff M, Pollmann M, Weyrauch KD, Amasheh S, Lodemann U, Jores J, Tachu B, Kleta S, Blikslager A, Tedin K, Wieler LH: Characterization of a porcine intestinal epithelial cell line for in vitro studies of microbial pathogenesis in swine. Histochem Cell Biol 2006, 125:293-305.

59. Line JE, Hiett KL, Guard-Bouldin J, Seal BS: Differential carbon source utilization by Campylobacter jejuni 11168 in response to growth temperature variation. J Microbiol Methods 2010, 80:198-202.

60. Darling AC, Mau B, Blattner FR, Perna NT: Mauve: multiple alignment of conserved genomic sequence with rearrangements. Genome Res 2004, 14:1394-1403.

61. Didelot $X$, Falush D: Inference of bacterial microevolution using multilocus sequence data. Genetics 2007, 175:1251-1266

62. Linton D, Owen RJ, Stanley J: Rapid identification by PCR of the genus Campylobacter and of five Campylobacter species enteropathogenic for man and animals. Res Microbiol 1996, 147:707-718.

63. Meinersmann RJ, Helsel LO, Fields PI, Hiett KL: Discrimination of Campylobacter jejuni isolates by fla gene sequencing. J Clin Microbiol 1997, 35:2810-2814.

64. Bang DD, Borck B, Nielsen EM, Scheutz F, Pedersen K, Madsen M: Detection of seven virulence and toxin genes of Campylobacter jejuni isolates from Danish turkeys by PCR and cytolethal distending toxin production of the isolates. J Food Prot 2004, 67:2171-2177. 
65. Bang DD, Nielsen EM, Knudsen K, Madsen M: A one-year study of campylobacter carriage by individual Danish broiler chickens as the basis for selection of Campylobacter spp. strains for a chicken infection model. Epidemiol Infect 2003, 130:323-333.

66. Linton D, Gilbert M, Hitchen PG, Dell A, Morris HR, Wakarchuk WW, Gregson NA, Wren BW: Phase variation of a beta-1,3 galactosyltransferase involved in generation of the ganglioside GM1-like lipo-oligosaccharide of Campylobacter jejuni. Mol Microbiol 2000, 37:501-514.

67. Malik-Kale P, Raphael BH, Parker CT, Joens LA, Klena JD, Quinones B, Keech AM, Konkel ME: Characterization of genetically matched isolates of Campylobacter jejuni reveals that mutations in genes involved in flagellar biosynthesis alter the organism's virulence potential. Appl Environ Microbiol 2007, 73:3123-3136.

68. Muller J, Meyer B, Hanel I, Hotzel H: Comparison of lipooligosaccharide biosynthesis genes of Campylobacter jejuni strains with varying abilities to colonize the chicken gut and to invade Caco-2 cells. J Med Microbiol 2007, 56:1589-1594.

69. Barnes $I H$, Bagnall MC, Browning DD, Thompson SA, Manning G, Newell DG: Gamma-glutamyl transpeptidase has a role in the persistent colonization of the avian gut by Campylobacter jejuni. Microb Pathog 2007, 43:198-207.

70. Ashgar SS, Oldfield NJ, Wooldridge KG, Jones MA, Irving GJ, Turner DP, Ala'Aldeen DA: CapA, an autotransporter protein of Campylobacter jejuni, mediates association with human epithelial cells and colonization of the chicken gut. J Bacteriol 2007, 189:1856-1865.

doi:10.1186/1471-2164-12-584

Cite this article as: Gripp et al: Closely related Campylobacter jejuni

strains from different sources reveal a generalist rather than a specialist lifestyle. BMC Genomics 2011 12:584.

\section{Submit your next manuscript to BioMed Central} and take full advantage of:

- Convenient online submission

- Thorough peer review

- No space constraints or color figure charges

- Immediate publication on acceptance

- Inclusion in PubMed, CAS, Scopus and Google Scholar

- Research which is freely available for redistribution

Submit your manuscript at www.biomedcentral.com/submit
Biomed Central 